LBL-31248 revised

UC-421

HIFAN 721

\title{
HEAVY ION DRIVEN LMF DESIGN CONCEPT*
}

\author{
Edward P. Lee
}

\section{Lawrence Berkeley National Laboratory \\ University of California \\ Berkeley, CA 94720}

July 1995

*This work was supported by the Director, Office of Energy Research, Office of Fusion Energy, U.S. Dept. of Energy, under Contract No. DE-AC03-76SF00098.

\section{MASTER}




\section{DISCLAIMER}

This report was prepared as an account of work sponsored by an agency of the United States Government. Neither the United States Government nor any agency thereof, nor any of their employees, make any warranty, express or implied, or assumes any legal liability or responsibility for the accuracy, completeness, or usefuiness of any information, apparatus, product, or process disclosed, or represents that its use would not infringe privately owned rights. Reference herein to any specific commercial product, process, or service by trade name, trademark, manufacturer, or otherwise does not necessarily constitute or imply its endorsement, recommendation, or favoring by the United States Government or any agency thereof. The views and opinions of authors expressed herein do not necessarily state or reflect those of the United States Government or any agency thereof. 


\section{DISCLAIMER}

Portions of this document may be illegible in electronic image products. Images are produced from the best available original document. 


\title{
HEAVY ION DRIVEN LMF DESIGN CONCEPT*
}

\author{
Edward P. Lee \\ Lawrence Berkeley National Laboratory \\ 1 Cyclotron Road \\ Berkeley, CA 94720
}

\section{Introduction}

From 1988 to 1991, the USA Department of Energy conducted a study of the requirements, designs and costs for a Laboratory Microfusion Facility (LMF). The primary purpose of the LMF would be testing of weapons physics and effects simulation using the output from microexplosions of inertial fusion targets. It does not need a high repetition rate, efficient driver system as required by an electrical generating plant; however there would be so many features in common that the design, construction and operation of an LMF would considerably advance the application of inertial confinement fusion to energy production. The DOE study concentrated particularly on the LMF driver, with design and component development undertaken at several national laboratories. Principally, these were LLNL (Solid State Laser), LANL (Gas Laser), and SNLA (Light Ions). Heavy Ions, although considered a possible LMF driver, did not receive attention until the final stages of this study since its program management was through the Office of Energy Research rather than Defense Programs. However, during preparation of the summary report for the study it was decided that an account of heavy ions was needed for a complete survey of the driver candidates. The conceptual heavy ion LMF driver design created for the DOE report did not receive the level of scrutiny of the other driver concepts and, unlike the others, no cost analysis by an independent contractor was performed. Since some heavy ion driver design lore was brought together in this exercise it is worthwhile to make it available as an independent report. This is reproduced here essentially as it appears as a section in Laboratory Microfusion Capability Study, Phase II Report, DOE/DP-0017, 1993.

\footnotetext{
* This work was supported by the Director, Office of Energy Research, Office of Fusion Energy, U.S. Dept. of
} Energy, under Contract No. DE-AC03-76SF00098. 
A rough estimate of the direct cost of the conceptual heavy ion driver (components, housing, utilities, diagnostics, controls, assembly and commissioning only) was made in 1991 but was not included in the DOE and LBL reports produced at that time. Due to renewed interest in the heavy ion LMF driver, that cost estimate has been updated and included here as an additional subsection (B9.). The present (1995) rough estimate based on 1990-91 cost projections is $918 \mathrm{M} \$$.

\section{A. DESIGN OVERVIEW}

\section{General Features of a Heavy Ion Driven LMF}

Major features of a $5 \mathrm{MJ}$, heavy ion driven LMF are outlined in this section, and driver details are given in section B. The facility would produce a $450 \mathrm{MJ}$ yield from a suitable, indirectly driven target, provided other requirements on spot size, peak power, etc. are also satisfied. Most LMF objectives of weapons-physics and effects-testing can be achieved at this level. Although it is not an optimal approach, a $10 \mathrm{MJ}$ driver with $1000 \mathrm{MJ}$ yield could be realized by duplicating the $5 \mathrm{MJ}$ driver and expanding the final transport and focal area. It is expected that a $5 \mathrm{MJ}$, low repetition rate system will also be a very valuable test bed for inertial fusion energy production, including target physics, chamber design, final focus and driver development. While no detailed cost breakdown was presented in the original 1991 report, the $5 \mathrm{MJ}$ driver was expected to cost about $\$ 1000 \mathrm{M}$ (FY 90 dollars, direct costs, without engineering and management included), extrapolated from a previous power plant study(1). The heavy ion driver type selected for this study is the multiple-beam induction linac, which is the conservative, nearer-term option that has received the most study in the USA. Selected ion type is $2.5 \mathrm{GeV} \mathrm{Kr}^{+}$(isotopically pure ${ }_{36} \mathrm{Kr}^{84}$ ) for low cost and source availability. Rubidium sources could be developed and used without a significant change in the system design. 


\section{Background}

A heavy ion ICF driver is recognized to be well-suited for the production of electrical power. (2) This is a result of the intrinsic high repetition rate, long life, reliability, and electrical efficiency of the accelerator. However, these features have reduced priority for an LMF, which would use a few pulses on targets per day at most. For very low repetition rate application, the present level of development of heavy ion drivers is behind that of solid state lasers (such as NOVA at LLNL). However, a 1987 study by Monsler(3) which examined cost reductions and scaling of major parameters achievable by modifying heavy ion power plant driver designs to meet LMF objectives, showed that this approach could be attractive at multi-megajoule levels.

It was decided to include an account of heavy ions in the Phase II report for several reasons. These included completeness of the study and the value of having an alternative for comparison with the three primary candidates. Also, a basis was laid for future consideration of a heavy ion driver that incorporates evolving technical features and cost projections.

The point design presented here represents a very small effort compared with that made for the three other drivers. This is partly a consequence of the location of the Heavy Ion Fusion Accelerator Research Program in the DOE Office of Basic Energy Sciences* rather than the Office of Inertial Fusion. There is no charter for a heavy ion LMF design, which is therefore only a modification of a power plant driver design. A single driver layout is presented here, which is the result of several iterations towards simplicity and compactness. In the DOE report (DOE/DP0017), no cost estimate was given for the heavy ion driver, however several obvious cost reducing modifications from a power plant driver were made. Since this design had not been previously included in the LMF study, a cost analysis could not be presented on the same basis as the other drivers; therefore none was given in the DOE report. However, the design does include an estimate of the dimensions of some of the principal components. The calculations of major parameters are also presented in moderate detail along with design formulas. These details

\footnotetext{
"Moved to the Office of Fusion Energy in 1991.
} 
allowed a rough estimate of the driver's direct cost; this has been included in the present, revised report.

\section{Selection of Accelerator Type}

Three distinct heavy ion driver accelerator types were put forward( ${ }^{(4)}$ in the early days of Heavy Ion Fusion: the synchrotron, the radio frequency (rf) linac, and the induction linac. The first two require storage rings to amplify ion current to the desired level, while the induction linac amplifies current during acceleration. The synchrotron was dropped from consideration early on, primarily because it was poorly matched to the desired energy and current (although it is of some value for the study of beam-matter interactions and beam dynamics, now underway at GSI Darmstadt(5) using the heavy ion synchrotron SIS and cooling ring ESR.) Acceleration by an rf linac was adopted by the European and Japanese programs and the HIBALL system study.(6) This is a relatively mature acceleration technology, but its technical risk for the fusion application is increased by the beam manipulations involved in transfers among linacs and storage rings. Further, the projected cost of an entire if driver system is large, leading to the use of multiple reactor chambers in a power plant to achieve an acceptable cost of electricity.

The induction linac driver is the primary approach pursued in the USA program at present. In its mainstream version multiple beams $(N \approx 4-64)$ are accelerated in a single linac $(1)$; otherwise, the accelerator is relatively simple in concept. Induction linac alternatives, intended to reduce cost (but with increased technical risk) are the multiple pulse induction linac (7) and the recirculator ${ }^{(8)}$. Due to its greater familiarity, lower risk, and lower development needs, the simple induction linac is adopted here for the heavy ion LMF design concept. The progression of heavy ion linacs leading to a fusion driver of this type is sketched in Table 1, which includes the existing LBL accelerators $\operatorname{SBTE}^{(9)}$ and $\mathrm{MBE}^{(10)}$, the proposed ILSE(11), and projections of large scale future machines. $(12,13)$ 
Table 1

Heavy Ion Linacs Leading to a Fusion Driver

\begin{tabular}{|c|c|c|c|c|c|}
\hline Name & Role & Ion & Kinetic Energy & $\begin{array}{c}\text { Number of } \\
\text { Beams }\end{array}$ & $\begin{array}{c}\text { Total } \\
\text { Energy }\end{array}$ \\
\hline SBTE & $\begin{array}{l}\text { Quadrupole Transport of Space } \\
\text { Charge Dominated Ion Beams }\end{array}$ & $\mathrm{Cs}^{+}$ & $150 \mathrm{kV}$ & 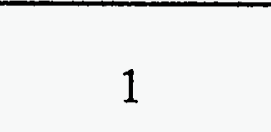 & - \\
\hline MBE & $\begin{array}{l}\text { Longitudinal and Transverse } \\
\text { Dynamics with Multiple Beams }\end{array}$ & $\mathrm{Cs}^{+}$ & $\begin{array}{l}200 \mathrm{KeV} \rightarrow \\
1.0 \mathrm{MeV}\end{array}$ & 4 & $0.08 \mathrm{~J}$ \\
\hline $\begin{array}{c}\text { ILSE } \\
\text { Proposed } 1989\end{array}$ & $\begin{array}{l}\text { Beam Dynamics, esp. with } \\
\text { Magnetic Quadrupoles and Bends }\end{array}$ & $\mathrm{C}^{+}$ & $\begin{array}{l}2.0 \mathrm{MeV} \rightarrow \\
10.0 \mathrm{MeV}\end{array}$ & $16 \rightarrow 4 \rightarrow 1$ & $\begin{array}{c}60-100 \mathrm{~J}, \\
1000 \mathrm{~J} \\
\text { upgrade }\end{array}$ \\
\hline $\begin{array}{l}\text { Intermediate } \\
\text { Facility } \\
1990 \text { Concept }\end{array}$ & $\begin{array}{l}\text { High Current Dynamics, } \\
\text { Component Development and } \\
\text { Integration }\end{array}$ & $\mathrm{K}^{+}$ & $100 \mathrm{MeV}$ & $84 \rightarrow 21$ & $30 \mathrm{~kJ}$ \\
\hline LMF & $\begin{array}{l}\text { Defense Applications and Power } \\
\text { Driver Development }\end{array}$ & $\mathrm{Kr}^{+}$ & $2.5 \mathrm{GeV}$ & 24 & $5.0 \mathrm{MJ}$ \\
\hline $\begin{array}{l}\text { Power Driver } \\
1990 \text { Concept }\end{array}$ & Prototype & $\mathrm{Hg}^{+}$ & $10.0 \mathrm{GeV}$ & $20 \rightarrow 4$ & $4.0 \mathrm{MJ}$ \\
\hline
\end{tabular}


Although no detailed comparison of the induction linac and if linac approaches is made here, typical power plant driver layouts for these systems (circa 1984) are shown in Figure 1. The essential distinctions between them are as follows:

(1) Acceleration with an If linac uses a well-established technology but is limited to low peak currents. The induction linac uses pulsed power technology which can drive high currents through an efficient, non-resonant energy transfer. This technology has been developed for light ion drivers, high current electron accelerators, and special accelerator components such as beam kickers.

(2) Current is increased in the rf linacs through $(2 \rightarrow 1)$ beam funneling operations between accelerators and the use of transfer and storage rings. An induction linac can increase current directly by pulse compression in time. Beam combining may also be employed. These operations are not well-developed for either approach at the relevant currents and are an area of current research and development.

(3) The outward appearance of simplicity of the induction linac is probably offset by the complications of multiple beam transport within its large diameter induction core structure. The if linacs accelerate single beams in smaller (but still large) resonant structures, but he complete if driver system is complicated by the use of many rings (equal to the number of beams).

(4) The if system has several stations involving beam manipulations, such as funneling or transfer, that can result in a loss of particles and beam quality. The induction linac must have accurate control of accelerating pulse forms at the moderate level of $\sim 1 \%$ to control beam quality.

(5) Issues of beam stability arise for the storage rings in the if approach and for the interaction of the beam with induction modules in the induction linac. Both appear solvable at present, but at some expense. 
(6) Residence time of beam in the rf system is one to two orders of magnitude longer than in the induction linac. This places a more severe vacuum requirement of the rf system.

(7) The two systems are essentially the same in final compression and final focus.

As mentioned, an LMF driver can differ from a power plant driver in repetition rate and efficiency. This allows some cost reduction features, which are exploited in the present design:

1) Small standoff distance of final focus lenses from fusion target reduces the size of final focus system and relaxes some beam requirements.

2) A vacuum environment in the target chamber eases the requirements for high speed shutters $(\sim 1.0 \mathrm{~ms})$ and rapid vacuum pumping at the chamber interface (which are characteristic of most power plant designs).

3) Pulsed, normal ( $\mathrm{Cu}$ wire) magnets may be used instead of supercónductors due to low pulse rate. These will also allow a moderate pulse rate $(\sim .1 \mathrm{~Hz})$ needed for preshot tuning.

4) Pulsed power components such as capacitors and high power switches can be rated for $\sim 10^{6}-10^{8}$ shots instead of $\sim 10^{10}$ as in a power driver.

The heavy ion driver program in the USA has concentrated on resolving beam dynamics issues for the 15 years of its existence. These have included studies of high current transport, beam compression, stability, high current source operation, multiple beam acceleration, electrostatic aberrations and other driver-related features. Scaled-down machines and experiments have demonstrated much of the fundamental accelerator physics and technology. Some areas of beam dynamics such as high current effects in magnetic quadrupole transport, bends and final focus have not yet been explored and are a subject of the near-term research program (ILSE). 
Most development needs have not been addressed due to a lack of resources, and no account of these is given here. However, all stages of the driver system employ large, high power versions of the components used in the present beam dynamics study program and can be assumed to require prototype development before an LMF or power driver can be realistically designed.

\section{Beam Requirements and Tradeoffs}

ICF requires high power (300-1000 TW) and total energy (2-10 MJ) deposited on the fusion target, roughly independent of driver type. However, unlike lasers, conversion efficiency to $\mathrm{x}$-rays is thought to improve with increased ion driver energy, and focal spot sizes can be larger by a factor of several. For an ion driver the depth of deposition in a stopper must be small $\left(\varsigma .1 \mathrm{gm} / \mathrm{cm}^{2}\right)$ to produce the necessary high temperatures. This range condition can be met in principle by any ion species accelerated sufficiently to match the range-energy relation (see Fig. 2). The very large stopping power for heavy ions in matter allows the use of kinetic energies up to 20 $\mathrm{GeV}$ for the highest masses. Required particle currents are therefore low compared with those for photons or light ions, but they are very high compared with those usually associated with heavy ion accelerators.

The target gain and peak power curves published by Bangerter and $\mathrm{Ho}^{(14)}$ are adopted as the starting point of design (Figs. 3,4). Here the target is indirectly driven with two-sided illumination. The clusters of ion beams heat a stopping material, and the typical range-energy curves computed (15) for hot ( $200 \mathrm{eV}$ ) Aluminum (Fig. 2) are assumed to be adequate for concept definition. After some design iterations, a consistent set of beam parameters at the target was selected (Table 2).

Although essentially similar, heavy ion-driven targets differ from laser-driven targets due to the different mode of energy disposition (Figure 5). Thus, although much information about target performance may be inferred from the laser and light ion experimental programs, heavy ion targets will be studied primarily by computer simulation for the foreseeable future (as in reference 
14). Data about range vs. energy and range shortening in hot dense plasmas, and other relevant plasma properties now available from the European program may be used for code validation.

Table 2. Beam Parameters at the Target

$\begin{array}{lcr}\text { Gain } & \text { (G) } & 90 \\ \text { Beam Energy } & \text { (W) } & 5 \mathrm{MJ} \\ \text { Target Yield } & \text { (Y) } & 450 \mathrm{MJ} \\ \text { Range } & \text { (R) } & 0.1 \mathrm{gm} / \mathrm{cm}^{2} \\ \text { Spot Radius } & \text { (r) } & 2.0 \mathrm{~mm} \\ \text { Ion Mass }\left(\mathrm{Kr}^{+}\right) & \text {(A) } & 83.9 \mathrm{amu} \\ \text { Peak Power } & \text { (P) } & 480 \mathrm{TW} \\ \text { Kinetic Energy } & \text { (T) } & 2.5 \mathrm{GeV}\end{array}$

Twenty five percent of the $5 \mathrm{MJ}$ beam energy is used for a prepulse (picket fence in time), so effective pulse length and peak (total) electric current are

$$
\begin{gathered}
\tau_{\mathrm{e}}=0.75 \mathrm{~W} / \mathrm{P}=7.81 \mathrm{~ns}, \\
\mathrm{I}=\mathrm{P} /(\mathrm{T} / \mathrm{e})=192 \mathrm{kA} .
\end{gathered}
$$

This current is too large to focus and transport directly to the target in two beams; it must be subdivided into many beams. A total of 24 individual beams are employed, with 18 in the peak power pulse and 6 arriving early to make up a prepulse. The peak current of an individual beam is then $I_{p}=192 / 18=10.67 \mathrm{kA}$. At this beam current level a $91 \%$ charge-neutralization fraction (in the chamber) must be supplied by co-injected electrons to allow the $2 \mathrm{~mm}$ focal spot. 
Several significant design tradeoffs are apparent, and the selected working point results from a balance among these. First, it is clear from figure 3 that reducing the spot radius increases gain if all other parameters are fixed; this would allow the use of a lower total energy for a fixed yield. However, reduced spot radius significantly increases technical risk in final focus and chamber transport. A more subtle scaling with smaller spot size is that the beams must occupy a smaller 6-d phase space during acceleration, which tightens tolerances on beam control, restricts potential ion sources, and possibly reduces the stable transportable current limit. Reduced range in the stopper also increases yield. This can be accomplished by either increasing ion mass or reducing kinetic energy. Ion mass has already been assumed very large for heavy ion drivers in order to get short ranges, and the switch to $\mathrm{Kr}^{+}$from (the sometimes assumed) $\mathrm{Hg}^{+++}$is motivated by the absence at present of a suitable, long pulse, high current source for the latter ion. Ion kinetic energy is reduced from $\sim 9 \mathrm{GeV}$ for $\mathrm{Hg}$ to $2.5 \mathrm{GeV}$ when we adopt $\mathrm{Kr}+$ in order to hold range at $\sim 0.1 \mathrm{gm} / \mathrm{cm}^{2}$. The similar values of charge to mass ratio and total accelerating voltage for these two ions insures that the drivers would be similar in size and cost. A further reduction in ion energy below $2.5 \mathrm{GeV}$ is expected to raise total driver cost due to a resulting low accelerating gradient at the low energy end and increased number of beams in the chamber associated with the increased total beam charge.

In summary, a broad optimum of driver cost is thought to exist around $2.5 \mathrm{GeV} \mathrm{Kr}^{+}$or $9 \mathrm{GeV} \mathrm{Hg}^{++}$. The latter ion would have a small advantage in cost if a source existed. For either ion a fairly high degree of charge neutralization is required in the chamber, and this is a technical issue which it is assumed will be favorably resolved. The alternative of $9.0 \mathrm{GeV} \mathrm{Hg}^{+}$ions would not require neutralization, but would require an appreciably longer and more expensive linac. A second, more expensive, solution to the space charge problem is to use a larger number of beams in final focus (preceded by a beam splitting operation). A third possibility, which is currently being studied, is to use self-pinched or discharge aided propagation in a gas filled chamber. 


\section{Chamber}

No study of chamber stress has been made for a heavy ion LMF. It is simply assumed here that a protected first wall at $2.0 \mathrm{~m}$ radius will be adequate (compare e.g., the $1.5 \mathrm{~m}$ first wall radius of a light-ion LMF). A $1.0 \mathrm{~m}$ thick layer for radiological shielding follows, which is penetrated by 24 beam ports of about $15 \mathrm{~cm}$ maximum diameter each. These ports are located in two clusters of 12 each on opposite sides of the chamber, with a maximum angular width between beam axes of $25^{\circ}$ in each cluster (see Fig. 6). The edge of the nearest final focus magnet is conservatively located at about $3.25 \mathrm{~m}$ radius to avoid heating of the insulated wire by neutrons. Neutralizing electron beams are co-injected parallel to the ions from grid sets located at about 2.75 $\mathrm{m}$ radius. These grids may be sacrificial. The concentration of beams into two groups of only moderate angular spread is a significant advantage of the heavy ion driver over lasers or light ioins for the LMF application. If additional space is required around the fusion target, the chamber could be designed with a radius larger than the assumed $2.0 \mathrm{~m}$. The last final focus magnets would stay at $3.25 \mathrm{~m}$ radius, but would be protected by a shield intruding into a chamber. Equivalently, in Figure 6 the chamber would bulge outwards in the plane normal to the beam groups.

The chamber is assumed to operate below $10^{-6}$ torr $\left(\mathrm{N}_{2}\right.$ or equivalent) vacuum, so that final focus can be differentially pumped without difficulty to $10^{-7}$ torr. Stripping of beam ions in final focus is then held to a negligible level and the co-injected electrons follow the beams without scattering. Although the low pulse rate allows vacuum operating conditions, it may be necessary to include fast shutters in the final focus beam lines to restrict radioactive vapors to a small portion of the driver system.

Line-of-sight neutrons in the beam ports do not intersect insulated magnet cable until the third quadrupole is reached at $\sim 15 \mathrm{~m}$ radius. This may not be a problem at the low LMF repetition rate, however by using quadrupoles with non-cylindrical aperture, line-of-sight neutrons can be dumped in absorbers located between magnets for the entire final focus system. 
The chamber must be equipped with vacuum seal doors for access, diagnostics, and beam ports.

\section{Beam Quality}

Beam spot radius is determined by at least five factors: transverse phase space area, space charge, second order chromatic aberration in final focus, third order geometric aberration in final focus, and jitter of all types. All of these effects are strongly dependent on the beam convergence half angle $(\theta)$. The aberrations are reduced by small $\theta$, and the other effects are reduced by large $\theta$. Here we set $\theta=20 \mathrm{mr}$, at which value geometric aberration can be essentially eliminated by design in final focus. The other four sources of spot size are assumed to be independent of each other and therefore contribute equally in the square, i.e. each individually would produce a spot radius $\tilde{r} \equiv\left(r^{2} / 4\right)^{1 / 2}=1.0 \mathrm{~mm}$.

Taking $\tilde{\mathrm{r}}$ to be an upper bound for radius produced by transverse phase space area, we have the limit on beam emittance (normalized edge value)

$$
\varepsilon_{\mathrm{n}} \leq \beta \theta \tilde{\mathrm{r}} \leq 5.06 \times 10^{-6} \mathrm{~m}-\mathrm{r},
$$

where

$$
\beta=\frac{v}{c}=.253 \text { for } 2.5 \mathrm{GeVK}_{\mathrm{I}}^{+}
$$

(non-relativistic formulas are used in this study.)

Momentum spread, assuming a four quadrupole final focus system with focal length/magnet $\mathrm{F}=4.0 \mathrm{~m}$, is approximately bounded by the chromatic aberration to the range

$$
\frac{\Delta \mathrm{p}}{\mathrm{p}} \leq \pm \frac{\tilde{\mathrm{r}}}{8 \mathrm{~F} \theta}= \pm 1.56 \times 10^{-3}
$$

This assumes that no second order optical correction scheme is used. 


$$
f \geq 1-\frac{\theta^{2}}{2 \kappa \log _{e}(F \theta / \tilde{r})}=.912
$$

where $\mathrm{K}$ is the dimensionless perveance of the focused beam in the chamber:

$$
\kappa=\frac{2 \mathrm{eI}}{\beta^{3} \mathrm{Mc}^{3} 4 \pi \varepsilon_{0}}=5.16 \times 10^{-4},
$$

and $I$ is taken to be $2 \%$ larger than the peak value in the target spot to allow for some loss of current.

\section{Summary of Major Parameters}

The major parameters of the LMF at or near the target are summarized in Table 3. 
Table 3

Summary of Major Parameters

Target Type

Target Yield

Beam Energy on Target

Peak Power on Target

Beam Spot Radius

Ion Range

Target Gain

Prepulse Energy Fraction

Number of Beams

Ion Type

Ion Mass

Ion Charge State

Ion Kinetic Energy

Effective Pulse Length

Total Charge on Target Spots

Beam Emittance

Beam Convergence Half Angle

12 Beam Group Angular Spread

Particle Velocity

Particle Rigidity

Peak Current Per Beam in Spot

Radius of First Wall

Standoff to First Magnet

Chamber Gas Pressure $\left(\mathrm{N}_{2}\right.$ at $\left.20^{\circ} \mathrm{C}\right)$

Momentum Spread

Beam Neutralization Fraction

by co-injected electrons
Indirect drive double-sided illumination

$450 \mathrm{MJ}$

$5.00 \mathrm{MJ}$

$480 \mathrm{TW}$

(r)

$2.00 \mathrm{~mm}$

(G) $.100 \mathrm{gm} / \mathrm{cm}^{2}$

90.0

$25 \%$

(N)

24

$\left(36^{\mathrm{Kr}^{84}}\right)^{+}$

(A)

$\left(\tau_{e}\right)$

$83.91 \mathrm{amu}$

$\left(\varepsilon_{n}\right)$

$+1$

$2.50 \mathrm{GeV}$

$7.81 \mathrm{~ns}$

$2000 \mu \mathrm{C}$ $<5.06 \times 10^{-6} \mathrm{~m}-\mathrm{r}$

$20.0 \mathrm{mr}$

$\pm 12.5^{\circ}$

$(\beta=v / c)$

.253

(Non-relativistic B $\rho$ )

$65.9 \mathrm{~T}-\mathrm{m}$

$\left(a_{p}\right)$

10660 Amp

$2.00 \mathrm{~m}$

$3.25 \mathrm{~m}$

$<10^{-6}$ torr

$\Delta \mathrm{p} / \mathrm{p}$

$< \pm 1.56 \times 10^{-3}$

(f)

$>91.2 \%$ 


\section{B. HEAVY ION DRIVER SYSTEM}

\section{General Features of an Induction Linac System for ICF (Power Production or LMF)}

An induction linac driver for ICF is now envisioned as a multiple-beam transport lattice . consisting of $\mathrm{N}$ closely packed, parallel FODO transport channels. Each focusing channel is composed of a periodic system of focusing (F) and defocusing (D) quadrupole lenses with acceleration gaps $(\mathrm{O})$ between successive lenses. Surrounding the transport structure are induction cores of ferromagnetic material with associated pulser circuitry that apply a succession of high-voltage pulses to the $\mathrm{N}$ parallel beams as they jointly pass through acceleration gaps. Longitudinal focusing is achieved through the detailed timing and shape of the accelerating waveforms (with feedforward correction of errors). A multiple-beam source of heavy ions operates at about $2 \mathrm{MV}$, producing the net charge per pulse required to achieve the desired target gain. Initial current and, therefore, initial pulse length are determined by transport limits at low energy, which are in turn dependent on injector voltage. ICF power driver designs often employ a large number of electrostatic quadrupole channels $(N=32-128)$ at low energies (below $\sim 100$ $\mathrm{MeV})$, followed by a lower number of superconducting magnetic channels $(\mathrm{N} \sim 4-32)$ for the rest of the accelerator. Merging of beams would therefore be required at the transition and some splitting of beams at final energy might be required to stay within current limits in final focus. A conceptually simpler, lower risk design with possibly higher cost makes use of magnetic quadrupoles for the entire system without combining or splitting. For a power driver these would be superconducting in order to achieve reasonable electrical efficiency. For the LMF design presented here we adopt the lower risk approach, with $N=24$.beams for the entire system. Pulsed magnets using copper wire may be employed since the repetition rate is very low. The use of pulsed, current dominated magnets (without iron poles) also allows field strengths approaching those attainable with superconducting wire.

The reason for the use of multiple beams is that it increases the net current that can be accelerated within a given cross section of core at a fixed accelerating gradient. Alternatively, a 
given amount of charge can be accelerated more rapidly with multiple beams since the pulse length is shortened and a core cross section of specified volt-seconds per meter flux-swing can supply an increased gradient. However, an increase in the number of beams of given current increases the dimensions and cost of the transport lattice and also increases the cost of the core for a given voltsecond product since a larger core volume is required. For a core of given cross sectional area (proportional to volt-seconds per meter), the volume of ferromagnetic material increases as its inside diameter is increased. Hence, there is a trade-off between transport and acceleration costs with an optimum at some finite number of beams. The determination of this optimum configuration is a complex problem depending on projected costs of magnets, core, insulators, energy storage, pulsers, and fabrication. However codes for optimizing a fusion power driver exist and could be modified for an LMF driver.

Induction cores (Fig. 7) are most likely to be constructed from very thin laminations (tape) of amorphous iron, which is the preferred material due to its large flux swing at a reasonable price. At a projected future cost of approximately $\$ 5.0 / \mathrm{kg}$ for insulated and wound tape, this is a major cost item for the first 1 to $2 \mathrm{GV}$ of a typical linac. Here it is assumed that a cheap insulator can be developed for tape, which is now available at $\sim 3.30 \$ / \mathrm{kg}$. At higher cumulative voltage, the cost of pulsers and fabrication of the high gradient column with vacuum insulators dominates cost projections for the acceleration module.

Between the accelerator and the fusion chamber, the beams are separated transversely in space. The $\mathrm{N}$ drift lines leading to the final focus area are 100 to $600 \mathrm{~m}$ long and used for ballistic compression as well as to match the final focus configuration into the chamber. This transport lattice is composed of high-field quadrupoles, bends, and possibly higher-order focal elements needed to control momentum dispersion and other sources of aberration. As the beams compress, the transport of the high current becomes increasingly demanding, with the large apertures and the close packing of quadrupoles especially pronounced immediately before the final focus area. 
The final focus system itself has parameters determined largely by the requirements of target spot size, fusion chamber size, beam rigidity (rigidity $=$ momentum/charge $=[\mathrm{Bp}]$ ), and the handling of neutrons, $\mathrm{x}$-rays, and gas flux from the chamber. The final focus magnet train is composed of four (or more) magnetic quadrupoles of large bore. With four quadrupoles its total length is approximately five times the focal length of an individual magnet.

\section{2. $\quad$ Pulse Structure}

The beam pulse length decreases dramatically between the injector operating at $2 \mathrm{MeV}$ and final focus at $2.5 \mathrm{GeV}$. Current increases accordingly, due both to acceleration and spatial compression. For the entire system the current profile is assumed to have a flat top, with rise and fall times equal to $1 / 11$ of total pulse duration $(\tau)$. Therefore the flat top is $9 / 11$ of the total and the effective pulse length $\left(\tau_{\mathrm{e}}=\right.$ charge/peak current) is $(10 / 11) \tau$. It is expected that some beam loss will occur through the system; to include this feature in the model, the loss is taken to be $2 \%$ at each major transition point. Pulse parameters for major components are given in Table 4. 
Table 4

Beam Pulse Parameters for Major LMP Components

\begin{tabular}{|l|c|c|c|c|}
\hline Component & $\begin{array}{c}\text { Total Pulse Charge } \\
(\mu \mathrm{C})\end{array}$ & $\begin{array}{c}\text { Cumulative Voltage } \\
(\mathrm{MV})\end{array}$ & $\begin{array}{l}\text { Total Beam } \\
\text { Pulse Length }\end{array}$ & $\begin{array}{l}\text { Peak Current } \\
\text { Per Beam }\end{array}$ \\
\hline Source/Injector & 2213 & $0.0 \rightarrow 2.0$ & $45.9 \mu \mathrm{s}$ & $2.21 \mathrm{~A}$ \\
\hline Matching Section & 2213 & 2.0 & $45.9 \mu \mathrm{s}$ & $2.21 \mathrm{~A}$ \\
\hline $\begin{array}{l}\text { Linac: } \\
\text { Low V Section }\end{array}$ & 2168 & $2.0 \rightarrow 25.6$ & $45.9 \rightarrow 3.58 \mu \mathrm{s}$ & $2.17 \rightarrow 27.8 \mathrm{~A}$ \\
\hline $\begin{array}{l}\text { Linac: } \\
\text { Medium V Section }\end{array}$ & 2168 & $25.6 \rightarrow 91.7$ & $3.58 \rightarrow 1.0 \mu \mathrm{s}$ & $27.8 \rightarrow 99.4 \mathrm{~A}$ \\
\hline $\begin{array}{l}\text { Linac: } \\
\text { High V Section }\end{array}$ & 2168 & $91.7 \rightarrow 2500$ & $1.0 \rightarrow .132 \mu \mathrm{s}$ & $99.4 \rightarrow 753 \mathrm{~A}$ \\
\hline $\begin{array}{l}\text { Drift } \\
\text { Compression }\end{array}$ & 2125 & 2500 & $132 \mathrm{~ns} \rightarrow 8.59 \mathrm{~ns}$ & $.737 \rightarrow 11.3 \mathrm{kA}$ \\
\hline $\begin{array}{l}\text { Final } \\
\text { Focus }\end{array}$ & 2082 & 2500 & $8.59 \mathrm{~ns}$ & $11.1 \mathrm{kA}$ \\
\hline $\begin{array}{l}\text { Chamber } \\
\text { (Neutralized) }\end{array}$ & 2041 & 2500 & $8.59 \mathrm{~ns}$ & $1.09 \mathrm{~A}$ \\
\hline \begin{tabular}{l} 
Target \\
\hline
\end{tabular} & 2000 & $2500 \rightarrow 0.0$ & $8.59 \mathrm{~ns}$ & $1.07 \mathrm{kA}$. \\
\hline
\end{tabular}

Total pulse charge takes into account a $2 \%$ loss at five locations. Peak current is 1.1 times mean current per beam ( $=$ total charge $/ 24 \times$ total pulse length). 


\section{Injector}

Twenty four beams of $2.0 \mathrm{MeV} \mathrm{Kr}^{+}$are supplied by a source/injector system, with peak current per beam of 2.21 amperes and total pulse length of $45.9 \mu \mathrm{s}$. Voltage control must be excellent $(< \pm 0.1 \%)$ to maintain sufficiently low occupied longitudinal phase space area. The source is a large area, gas discharge with ions exiting a highly perforated cathode held about 100 $\mathrm{kV}$ below the $+2 \mathrm{MV}$ discharge volume. Sources of this type are an extrapolation from the long pulse type developed for neutral beam heating of magnetic fusion devices and are also similar to the large aperture $\mathrm{Cs}^{+}$and $\mathrm{Hg}^{+}$sources developed for application as ion thrusters for space craft propulsion. The remaining $~ 1.9 \mathrm{MV}$ of the injector is a high gradient column, with aperture focusing provided by voltage grading corresponding approximately to the Child-Langmuir Law (i.e. $\mathrm{V}(\mathrm{x}) \propto \mathrm{x}^{4 / 3}$ ).

An estimate of injector parameters is readily made. Taking the maximum injector gradient be $5 \mathrm{MV} / \mathrm{m}$ we find column length

$$
\mathrm{d}=\frac{4}{3} \frac{\mathrm{V}}{\varepsilon_{\max }}=.533 \mathrm{~m}
$$

By applying the C-L current density law

$$
\mathrm{j}=5.46 \times 10^{-8} \sqrt{\frac{\mathrm{qV}^{3}}{\mathrm{Ad}^{4}}}=59.4 \mathrm{~A} / \mathrm{m}^{2},
$$

we obtain the beam radius

$$
a_{s}=\sqrt{\frac{I}{\pi j}}=.109 \mathrm{~m}
$$

This radius is approximately double that desired for a beam in the induction linac, so a matching system with bends must connect the injectors to the accelerator. This would require about 5 quadrupoles and 2 bends per beam. The source discharge is expected to produce very low temperature ions $(<.5 \mathrm{eV})$. Assuming an effective value $\mathrm{T}_{\mathrm{s}} \leq 1 \mathrm{eV}$, which includes injector aberrations, we find initial emittance 


$$
\varepsilon_{\mathrm{n}}=6.55 \times 10^{-5} \sqrt{\frac{\mathrm{T}_{\mathrm{s}}}{\mathrm{A}}} \mathrm{a}_{\mathrm{s}} \leq 7.79 \times 10^{-7} \mathrm{~m}-\mathrm{r}
$$

a value 6.5 times smaller than the design limit for final focus. Elimination of mechanisms causing emittance growth through the entire driver is therefore important.

In order to make an injector system of manageable dimensions, the 24 beams are produced in four groups of six each. Each group of 6 would have a high voltage power supply in common, possibly employing large, amorphous iron blocking cores similar to those of the linac.

\section{Beam Transport}

The multiple-beam quadrupoles that transport the heavy ions through the linac are built up of $\mathrm{Cu}$ cable wrapped close to the beam channels and backed by laminated, non-magnetic steel collars. High fields $(B \sim 5 T)$ can be realized in this configuration by short pulse operation, with enough time interval between pulses for cooling to ambient. In the present design, a maximum temperature rise of $20^{\circ} \mathrm{C}$ is produced in $5 \mathrm{~ms}$ operation with $6 \times 10^{8}$ Amperes $/ \mathrm{m}^{2}$ average in the insulated cable. Peak field at the wire is $\sim 3.8 \mathrm{~T}$, producing a stress of about $5000 \mathrm{psi}$ in the collar.

All magnets are identical in their transverse dimensions, but their lengths increase by a factor of several over the first $92 \mathrm{MV}$ of the linac. Specific beam and magnet parameters at the lowest energy are given in Table 5.

Approximate relations for quadrupole transport of intense non-relativistic ion beams were used to construct Table 5; these are summarized in an Appendix. 


\section{Table 5}

Transport Parameters at $2 \mathrm{MV}$

Ion Mass $\left(\mathrm{Kr}^{+}\right)$

Kinetic Energy

Peak Beam Current

Beam Edge Radius

Transport Tune

Depressed Tune

Velocity/c

Rigidity

Magnet Aperture

Wire Inner Radius

Wire Outer Radius

Field Gradient

Lattice Half Period Length

Magnet Effective Field Length

The phase advance per period (tune $\sigma_{0}$ ) of $72^{\circ}$ is selected to ensure that the entire pulse is free from an envelope instability associated with $\sigma_{0}>85^{\circ}$. The depressed tune of $2.5^{\circ}$ is consistent with the source emittance. A significant feature of the magnets is their large aspect ratio $\mathrm{R} / \eta \mathrm{L}=.445$ at the lowest energy. Special design consideration is necessary to minimize aberrations at this stage, but there is little concern for this over this for most of the machine.

The beams' space charge force nearly cancels the mean focusing action of the quadrupoles. This is a consequence of the relatively large value of the current for the required emittance, and is reflected in the very low ratio of depressed tune to transport tune $\left(\sigma / \sigma_{0} \propto \varepsilon_{\mathbf{n}} \mathrm{V} \sigma_{\mathrm{o}} / \mathrm{LI}\right)$ .Experimental demonstration $(9)$ of transport using electrostatic quadrupoles (SBTE) has shown 
stability down to $\sigma / \sigma_{0} \approx .1$, limited only by available source emittance. The lower ratio $\sigma / \sigma_{0} \approx$ .035 assumed here is expected to be stable for magnetic transport, based on PIC simulations.(16)

Magnet length increases during acceleration at a rate which balances space charge forces while maintaining constant beam radius and magnetic field gradient. The essential scale relations for quadrupole field occupancy $(\eta)$ and half period length (L) are then approximately

$$
\begin{aligned}
& \eta L^{2} \mathrm{~V}^{-1 / 2}=\text { constant }, \\
& \mathrm{IL}^{2} \mathrm{~V}^{-3 / 2}=\text { constant },
\end{aligned}
$$

where $I$ is peak beam current and $V$ is cumulative accelerating voltage.

In the low and medium energy linac sections $\left(\mathrm{V}_{0}<\mathrm{V}<\mathrm{V}_{2}=91.7 \mathrm{MV}\right)$ we have

$$
\begin{gathered}
\eta=.476, \\
L=.382\left(V / N_{0}\right)^{1 / 4} \mathrm{~m},
\end{gathered}
$$

so at $V_{2}, L=.994 \mathrm{~m}$ and the effective magnet length is $\eta L=.473 \mathrm{~m}$. For the high energy section $\eta \mathrm{L}$ is the constant value $.473 \mathrm{~m}$, while $\eta$ decreases gradually to .110 and $\mathrm{L}$ increases to $4.30 \mathrm{~m}$.

\section{Acceleration Section Parameters}

\section{1 . Low energy section $\left(\mathrm{V}_{0}=2 \mathrm{MV}<\mathrm{V}<25.6 \mathrm{MV}=\mathrm{V}_{1}\right)$}

The rate of acceleration at the lowest energy is limited by beam dynamics; in order to avoid a degradation of transport, the pulse tail is not allowed to have velocity significantly larger than the pulse head. The assumed requirement is $\Delta v / v \leq .3$ at any station in the accelerator, where $\Delta v=$ $\left(v_{\text {tail }}-v_{\text {head }}\right)$ and $v=\left(v_{\text {tail }}+v_{\text {head }}\right) / 2$. The "velocity tilt" $\Delta v / v$ is the consequence of both acceleration and longitudinal compression. A useful relation is 


$$
\frac{\Delta \mathrm{v}}{\mathrm{v}}=\frac{\varepsilon \ell}{\mathrm{V}}\left[\frac{1}{2}-\frac{\mathrm{V}}{\ell} \frac{\mathrm{d} \ell}{\mathrm{dV}}\right]
$$

where $\varepsilon$ is the smoothed, local system gradient, $\ell=v \tau$ is pulse length given in meters, and $V$ is cumulative voltage. In the low energy section compression and acceleration are taken to contribute equally to tilt $\left(\ell \propto \mathrm{V}^{-1 / 2}\right)$. We find at $\mathrm{V}_{\mathrm{o}}=2 \mathrm{MV}$ :

$$
\begin{gathered}
\tau_{\mathrm{o}}=45.9 \mu \mathrm{s} \text { (total pulse durations are given) } \\
\varepsilon_{\mathrm{o}}=6.10 \mathrm{kV} / \mathrm{m} \\
\iota_{0}=98.4 \mathrm{~m} \\
\varepsilon_{\mathrm{o}} \tau_{\mathrm{o}}=.280 \mathrm{~V}-\mathrm{s} / \mathrm{m}
\end{gathered}
$$

and for $V_{0}<V<V_{1}=25.6 M V$ the scaling with $V$ is

$$
\begin{gathered}
\tau=\tau_{0} \mathrm{~V}_{0} / \mathrm{V} \\
\ell=\varepsilon_{0}\left(\mathrm{~V}_{0} / \mathrm{N}\right)^{1 / 2}, \\
\varepsilon=\varepsilon_{0}\left(\mathrm{~V} / \mathrm{V}_{0}\right)^{3 / 2} \\
\varepsilon \tau=\varepsilon_{0} \tau_{0}\left(\mathrm{~V} / \mathrm{V}_{0}\right)^{1 / 2}
\end{gathered}
$$

Acceleration in this manner continues to $\mathrm{V}_{1}$, where the volt-sec product reaches $1.0 \mathrm{~V}-\mathrm{s} / \mathrm{m}$. At this point we have

$$
\begin{gathered}
\tau_{1}=3.58 \mu \mathrm{s}, \\
\varepsilon_{1}=27.5 \mathrm{~m}, \\
\varepsilon_{1}=279 \mathrm{kV} / \mathrm{m} .
\end{gathered}
$$


Total section length, volt sec product, and number of lattice half periods are readily obtained for $\mathrm{V}_{\mathrm{o}}<\mathrm{V}<\mathrm{V}_{1}$ :

$$
\begin{gathered}
\text { Low energy section length }=\int \frac{d V}{\varepsilon}=472 \mathrm{~m}, \\
\text { Volt-sec total }=\int \frac{\mathrm{dV}}{\varepsilon} \varepsilon \tau=234 \mathrm{~V}-\mathrm{s}, \\
\text { Half periods }=\int \frac{\mathrm{dV}}{\varepsilon \mathrm{L}}=373 .
\end{gathered}
$$

5.2 Medium energy section $\left(\mathrm{V}_{1}=25.6 \mathrm{MV}<\mathrm{V}<\mathrm{V}_{2}=91.7 \mathrm{MV}\right)$

Here, acceleration is limited by core size -- we restrict $\varepsilon \tau$ to be $1.0 \mathrm{~V}-\mathrm{s} / \mathrm{m}$ (the total flux swing per $\mathrm{m}$ is $\sim 20 \%$ larger than this value). Compression as $\ell \propto \mathrm{V}^{-1 / 2}$ continues, so the scale relations are

$$
\begin{aligned}
\frac{\Delta \mathrm{v}}{\mathrm{v}} & =.3\left(\mathrm{~V}_{1} / \mathrm{V}\right)^{1 / 2} \\
\tau & =\tau_{1}\left(\mathrm{~V}_{1} / \mathrm{V}\right) \\
\varepsilon & =\varepsilon_{1}\left(\mathrm{~V} / \mathrm{V}_{1}\right)
\end{aligned}
$$

This schedule applies up to $\mathrm{V}_{2}=91.7 \mathrm{MV}$, where gradient $\varepsilon_{2}=1.0 \mathrm{MV} / \mathrm{m}$ is reached. We then have

$$
\begin{gathered}
(\Delta v / v)_{2}=.158 \\
\tau_{2}=1.0 \mu \mathrm{s} \\
\ell_{2}=14.5 \mathrm{~m} .
\end{gathered}
$$

Summary for medium energy section:

Medium energy section length $=117 \mathrm{~m}$, 
Section core $=117$ Volt-sec,

Section half periods $=139$.

5.3 High energy section $\left(V_{2}=91.7 \mathrm{MV}<\mathrm{V}<2.5 \mathrm{GV}=\mathrm{V}_{3}\right)$

Acceleration gradient $\varepsilon$ is now limited by the breakdown field of vacuum insulators for finite duration pulses. A conservative relation between mean gradient and pulse length is achieved with

$$
\varepsilon=\varepsilon_{2}\left(V / V_{2}\right)^{1 / 4}
$$

Pulse compression continues to a minor degree, but is brought to a halt at $\ell=10.0 \mathrm{~m}$ to keep the longitudinal space charge field of the beams within manageable bounds. While there is no physical limit here it would be inconvenient to devote major resources to keeping a short bunch together. To achieve a smooth transition at $V_{2}$ and satisfy the gradient and pulse length conditions in the high energy section we take

$$
\begin{gathered}
\ell=\ell_{2}\left[1+\frac{\sqrt{\mathrm{V} / \mathrm{V}_{2}}-1}{1+1.97\left(\sqrt{\mathrm{V} / \mathrm{V}_{2}}-1\right)}\right]^{-1}, \\
\tau=\tau_{2} \sqrt{\frac{\mathrm{V}_{2}}{\mathrm{~V}}} \frac{\ell}{\ell_{2}} .
\end{gathered}
$$

Then as $\mathrm{V}$ reaches the final value $2.5 \mathrm{GV}$ we have the final values

$$
\begin{gathered}
\varepsilon_{3}=2.28 \mathrm{MV} / \mathrm{m} \\
\tau_{3}=.132 \mu \mathrm{s}, \\
\ell_{3}=10 \mathrm{~m}
\end{gathered}
$$


The particular formulas given for $\mathcal{2}$ and $\varepsilon$ guarantee that tilt $\Delta \mathrm{v} / \mathrm{v}$ is continuous at the $91.7 \mathrm{MV}$ transition point.

Summary for high energy section:

High energy section length $=1336 \mathrm{~m}$,

Section core $=568$ Volt-sec. ,

Section lattice periods $=521$.

Total length, core and half periods for the entire linac are:

$$
\begin{aligned}
& \text { Length }=1925 \mathrm{~m}, \\
& \text { Core }=919 \text { Volt-sec. } \\
& \text { Half periods }=1033 .
\end{aligned}
$$

\section{Drift-Compression}

A large amplification of beam power is possible subsequent to acceleration. The beam pulse length is reduced by a factor of $\sim 15.3$ between the linac and final focus by drift-compression. During the final stages of acceleration a large velocity tilt is re-imposed for this purpose through the use of ramped waveforms in the induction modules (this is not included in the calculations of Sec. 5.3). Longitudinal space charge force removes this tilt by the time the beam reaches final focus. The consistent parameter set in this design is: drift distance to middle of final focus system $=159 \mathrm{~m}$, initial tilt $\Delta v / v=.0667$, assuming the space charge weight factor is $g=2 \log _{e}(R / \bar{a})=$ .81. Transport into the final focus configuration requires bends up to $4.0 \mathrm{~T}$ field strength and quadrupoles of increased aperture. A $50 \mathrm{~m}$ mean radius of curvature is adequate for the bend system; thus bend magnet occupancy fraction is the moderate value

$$
\eta_{\text {bend }}=\frac{\text { ion rigidity }}{\mathrm{B} \times \text { mean radius }}=\frac{65.9}{4 \times 50}=.330
$$


In order to transport the increasing current, half period length is gradually decreased by a factor of $\sqrt{3}$ to $2.48 \mathrm{~m}$, and aperture radius increased by $\sqrt{5.1}$. Then $I \propto(R / L)^{2}$ allows transport of the increased current by the desired factor of 15.3. Quadrupole occupancy fraction increases from an initial value $\eta=.110$ to a final $\eta=.365$, holding gradient $B^{\prime}=39.5 \mathrm{~T} / \mathrm{m}$. Magnetic field at the wire rises to $\sim 8.5 \mathrm{~T}$, indicating the use superconductor for at least this portion of the system. A detailed layout of this section would include additional magnets needed to maintain first, and possibly second order, achromaticity.

\section{Final Focus}

Four large-aperture quadrupoles per beam are adequate for a final focus set. These are laid out as shown in Fig. 8. The focal length $(\mathrm{F})$ is $4.0 \mathrm{~m}$ for all four magnets. Vertical and horizontal beam envelope radii are also shown in Fig. 8 as calculated using the thin lens approximation. Note that the maximum beam radius is $3 F \theta=.24 \mathrm{~m}$, which occurs in the central pair of quadrupoles; these must be much larger than the others. A point-to-point focus is produced by the layout; this is an adequate approximation for the purpose of obtaining field strengths and sizes. However, a detailed design would take into account space charge, geometric aberrations, thick lenses, and possibly chromatic corrections. Approximate field strength in each quadrupole is obtained from the thin lens formula

$$
B\left(R_{a}\right)=B^{\prime} R_{a}=\frac{[B \rho] R_{a}}{L_{m} F},
$$

where $[B p]=65.9 \mathrm{~T}-\mathrm{m}$ is ion rigidity, $\mathrm{R}_{\mathrm{a}}$ is aperture radius, and $\mathrm{L}_{\mathrm{m}}$ is effective magnet length. The latter quantity is selected to keep fields as low as possible while allowing room for beam line hardware. Table 6 gives parameter values for large and small final focus quadrupoles 
Table 6

Final Focus Parameters

\begin{tabular}{|c|c|c|c|}
\hline & $\ell_{\mathrm{m}}$ & $\mathbf{R}_{\mathbf{a}}$ & $\mathbf{B}\left(\mathbf{R}_{\mathbf{a}}\right)$ \\
\hline Small Quadrupoles & $1.0 \mathrm{~m}$ & $.14 \mathrm{~m}$ & $2.31 \mathrm{~T}$ \\
\hline Large Quadrupoles & $2.0 \mathrm{~m}$ & $.28 \mathrm{~m}$ & $2.31 \mathrm{~T}$ \\
\hline
\end{tabular}

The actual length of a magnet is about $1.5 \varepsilon_{\mathrm{m}}$, and the aperture radii have been set $\sim 17 \%$ above the maximum beam radii in the magnets. Field strengths are low enough that pulsed $\mathrm{Cu} / \mathrm{steel}$ magnets may be used. The full diameter of the large magnets is $1.0 \mathrm{~m}$; this determines the $\pm 12.5^{\circ}$ angular spread among beam centers.

\section{Concept Validation}

Here, only a list of requirements will be given; these are separated into the several broad areas:

Dynamics of space charge dominated beams

Special considerations for high power beams

Development of accelerator components

Diagnostics and controls for a large multiple beam induction linac

Cost reduction of accelerator components

Handling high energy ion beams in the experimental area

(1) Dynamics of Space Charge Dominated Beams. This covers stability, emittance growth and general control of beams in which the space charge force nearly cancels the mean focusing effect of the quadrupole channel. The existing experiments, SBTE and MBE, address relevant issues with low current beams $(\leq 20 \mathrm{~mA})$ transported over a distance of $\sim 20 \mathrm{~m}$. Some acceleration and multiple beam $(N=4)$ effects have been studied, including current 
amplification by a factor of 8 . The proposed Induction Linac System Experiment (KLSE) will extend this study in several directions, including the use of magnetic quadrupoles, a high voltage injector, bends, drift compression, beam combining and neutralized focus. Low current dynamics should be essentially resolved by ILSE.

(2) High Power Beams. A large current of ions ( $>100 \mathrm{~A}$ total) loads the induction modules and thereby acts back on itself. This interaction makes accelerating waveform control more complicated. In addition, a bunching mode instability is predicted(5). The resolution of these phenomena involves developing appropriate waveform and beam current monitors, and feed-forward correction circuitry.

A second area of high current effects is the short time-scale degradation of vacuum by beam spill. That is, loss of particles near the beam head can generate an electron cloud which affects transport in the beam tail; this is not as severe an issue for a linac as for a storage ring.

Third, at very high currents the process of neutralization by electrons after final focus may (or may not) prove difficult to generate with sufficiently low temperature on the nanosecond time scale.

(3) Development of accelerator components. Large induction modules with associated pulser circuitry need to be developed. The goal here is to achieve the desired electrical properties of voltage standoff, impedance and efficiency in a reasonably economical and robust package.

A second area of necessary development is multiple beam quadrupole arrays with adequate field quality and resistance to mechanical and thermal stress.

The $30 \mathrm{~kJ}$ intermediate facility appearing on Table 1 would be a useful test bed for categories (2) and (3) (although it is not part of current national planning).

(4) Diagnostics and controls for a large multiple beam induction linac. A driver scale linac requires monitoring of beam and magnet positions and a system to make adjustments in alignment. This is somewhat more complex than is usual for accelerators due to the use of 
multiple beams. Beam steering must take into account the large velocity tilt in the low energy sections.

(5) Cost reduction of accelerator components. At present amorphous iron tape for induction cores is available for $-3.30 / \mathrm{kg}$, but an insulating procedure raises the cost by up to an order of magnitude. This price must be reduced to make the induction.linac attractive. A second large cost item is the pulser switch and energy storage system. A projected cost of $\$ 10 /$ Joule might be realized with special design appropriate for the heavy ion system, i.e., relatively low rep rate and long pulse compared with existing electron induction linacs.

(6) Handling high energy ion beams in the experimental areas. The heavy ion driver described here employs large magnets and moderate vacuum $\left(\mathrm{P} \leqq 10^{-5}\right.$ torr)close to the target chamber. There are therefore unique interface requirements. These include integration of the neutralization system, fast shutters, space frame and alignment system for magnets, and shielding of activation by the ion beam.

\section{Cost Estimate}

In 1991 a rough cost estimate was made for the heavy ion LMF driver described in this report, but it was not included in the final DOE phase II report because it was not reviewed along with the other three driver concepts. This cost estimate is summarized here, with very minor changes from 1991.

Only the direct cost of the driver is given here; this consists of purchased components, driver tunnel and buildings, installation, and commissioning. Therefore costs for the following are excluded:

Engineering

Laboratory and Government Management

Site

Replacement Components

Laboratory offices 


\section{Experimental Area}

\section{Target Factory}

Site improvements not directly connected to the driver

\section{Contingency}

Laboratory overhead or other burdens.

The component costs are essentially unchanged from 1990-91, and were based at that time on figures used in LLNL recirculating induction accelerator driver studies ${ }^{(8)}$ and informed estimates from induction linac engineers at LBL. Generally the components require development to fit this particular application (see section 8). In the latter category are the amorphous iron induction cores and the pulse forming networks which power them. The cost of necessary safety features are included in tunnel, buildings, diagnostics and controls costs.

\subsection{Component Costs}

(a) Multibeam injectors. Six complete units accelerating four beams each to $2.0 \mathrm{MV}$ are estimated to cost $10.00 \mathrm{M} \$$ each based on experience with the ETA and ATA electron injectors:

$$
6 \times 10.00 \mathrm{M} \$=60.00 \mathrm{M} \$ \text {. }
$$

(b) Matching sections from injectors to the linac consist of twenty-four short beamlines of seven magnets each and associated power supplies and misc. hardware [see (g) and (h) below]:

24 lines $\times 7$ magnets $\times(\$ 2772 /$ magnet $+\$ 2500 /$ power supply)

x 2 (misc. other hardware) $=1.77 \mathrm{M} \$$

(c) Linac cores. Amorphous iron cores to be pulsed to $\sim 100 \mathrm{kV}$ each are assurned to be available in quantity at $\$ 5$ per $\mathrm{kg}$, which includes winding and insulation. The assumed "flux swing" is $2.5 \mathrm{~T}$, and the packing fractions are $80 \%$ in both the radial and longitudinal directions. The core inner radius is $.879 \mathrm{~m}$ throughout the machine, 
determined by the outer radius of the 24 beam magnet array and gap insulator. The outer radius of the core packages ranges from $1.05 \mathrm{~m}$ to $1.2 \mathrm{~m}$ depending on the required volt-second product per $\mathrm{m}$. Masses and costs are summarized as follows:

\begin{tabular}{l|l|l} 
Acceleration Zone & Core Mass & Cost at $\$ 5 / \mathrm{kg}$ \\
\hline low energy & $4.347 \times 10^{6} \mathrm{~kg}$ & $21.74 \mathrm{M} \$$ \\
medium energy & $2.450 \times 10^{6} \mathrm{~kg}$ & $12.25 \mathrm{M} \$$ \\
high energy & $10.53 \times 10^{6} \mathrm{~kg}$ & $52.65 \mathrm{M} \$$ \\
\hline Linac cores total & $17.33 \times 10^{6} \mathrm{~kg}$ & $\underline{86.64 \mathrm{M} \$}$
\end{tabular}

(d) Linac Module Structures consist of 5000 units averaging $500 \mathrm{kV}$ acceleration each and averaging $.385 \mathrm{~m}$ in length. The average cost at $\$ 10,000 / \mathrm{m}$, which includes alignment features and bellows, is $\$ 3850$ :

$$
5000 \times \$ 3850=19.25 \mathrm{M} \$ \text {. }
$$

(e) Linac High Voltage Insulators hold an average of $500 \mathrm{kV}$ in each module. They are estimated to cost $\$ 5000$ each:

$$
5000 \times \$ 5000=25.00 \mathrm{M} \$ \text {. }
$$

(f) Pulse Forming Networks operate at the relatively low level of $\sim 100 \mathrm{kV}$ with efficiency to the beam load averaging $1 / 3$. Due to beam loss during transport to the target it is actually necessary to provide $1.085 \times 5 \mathrm{MJ}$ beam energy. Priced at $\$ 10$ per Joule at the PFN we have:

$$
\left(1.085 \times 5 \times 10^{6} \mathrm{~J}\right) \times(\$ 10 / \mathrm{J}) \times(3 \text { efficiency })=162.75 \mathrm{M} \$ .
$$

(g) Linac Quadrupole Magnets are priced at $\$ 33$ per $\mathrm{kg}$ and weigh $84 \mathrm{~kg}$ each. An indentical pulsed quadrupole is placed in each of the 24 beam channels for all of the 1032 lattice half periods:

24 beams $\times 1032$ half periods $\times 84 \mathrm{~kg} \mathrm{x} \$ 33 / \mathrm{kg}=68.66 \mathrm{M} \$$. 
(h) Linac Magnet Power Supplies are costed at $\$ 2500$ each and employed at one per magnet:

24 beams $x 1032$ half periods $x \$ 2500=61.92 \mathrm{M} \$$.

(i) Linac Vacuum has an internal surface area of approximately $7620 \mathrm{~m}^{2}$. Pressure of $\sim 10^{-9}$ torr is maintained by 28 roughing pumps at $\$ 30,000$ ea. and 467 cryogenic pumps at $\$ 20,000$ ea.:

$$
28 \times \$ 30,000+467 \times \$ 20,000=10.18 \mathrm{M} \$ .
$$

(j) Linac Tunnel has $151,100 \mathrm{ft}^{2}$ area at $\$ 58 / \mathrm{ft}^{2}$ :

$$
151,100 \times \$ 58=8.76 \mathrm{M} \$ \text {. }
$$

(k) PFN Building, located above the Linac tunnel, has $163,200 \mathrm{ft}^{2}$ at $\$ 50 / \mathrm{ft}^{2}$ :

$$
163,200 \times \$ 50=8.16 \mathrm{M} \$ \text {. }
$$

(1) Transport Line Components from the linac to the final focus are priced in approximate accord with Tevatron, SSC and other recent high energy accelerator systems at $\$ 20,000 / \mathrm{m}$. This includes magnets, power supplies, vacuum, structure, bellows, and alignment features. Each of the 24 lines is $159 \mathrm{~m}$ long:

$$
24 \times 159 \times \$ 20,000=76.32 \mathrm{M} \$ \text {. }
$$

(m) Transport Line Building is a high ceiling concrete structure shielding a moderate rảdiation hazard produced by beams and micro-explosions. $53,800 \mathrm{ft}^{2}$ are priced at $\$ 174 / \mathrm{ft}^{2}$ :

$$
53,800 \times \$ 174=9.36 \mathrm{M} \$ \text {. }
$$

(n) Final Focus Quadrupoles weigh $18,000 \mathrm{~kg}$ per beam line and are costed at $\$ 33 / \mathrm{kg}$ :

$$
24 \times 18,000 \times \$ 33=14.26 \mathrm{M} \$ \text {. }
$$

(o) Final Focus Power Supplies are costed at $90 \%$ of magnets:

$$
.9 \times 14.26 \mathrm{M} \$=12.83 \mathrm{M} \$ \text {. }
$$

(p) Interface to the Target Chamber occupies about $2 \mathrm{~m}$ length per beam line of assorted pumping, electron sources, and shutters. This is costed at $\$ 100,000 / \mathrm{m}$ :

24 beams $\times 2 \mathrm{~m} \times \$ 100,000 / \mathrm{m}=4.80 \mathrm{M} \$$. 


\subsection{Cost Summary}

'Components, Tunnel and Buildings

$\begin{array}{llr}\text { (a) } & \text { Multibeam injectors } & 60.00 \mathrm{M} \$ \\ \text { (b) } & \text { Matching sections } & 1.77 \mathrm{M} \$ \\ \text { (c) } & \text { Linac cores } & 86.64 \mathrm{M} \$ \\ \text { (d) } & \text { Linac Module Structures } & 19.25 \mathrm{M} \$ \\ \text { (e) } & \text { Linac High Voltage Insulators } & 25.00 \mathrm{M} \$ \\ \text { (f) } & \text { Pulse Forming Networks } & 162.75 \mathrm{M} \$\end{array}$

(g) Linac Quadrupole Magnets $\quad 68.66 \mathrm{M} \$$

(h) Linac Magnet Power Supplies $\quad 61.92 \mathrm{M} \$$

(i) Linac Vacuum $10.18 \mathrm{M} \$$

(j) Linac Tunnel $\quad 8.76 \mathrm{M} \$$

$\begin{array}{ll}\text { (k) PFN Building } & 8.16 \mathrm{M} \$\end{array}$

(l) Transport Line Components $\quad 76.32 \mathrm{M} \$$

(m) Transport Line Building $\quad 9.36 \mathrm{M} \$$

$\begin{array}{ll}\text { (n) Final Focus Quadrupoles } & 14.26 \mathrm{M} \$\end{array}$

(o) Final Focus Power Supplies $\quad 12.83 \mathrm{M} \$$

(p) Interface to the Target Chamber $4.80 \mathrm{M} \$$

$630.66 \mathrm{M} \$$

Special Utilities at $2 \%$ of components, tunnel, and buildings $\quad 12.61 \mathrm{M} \$$

Diagnostics and controls at $10 \%$ of components, tunnel, and

buildings

$63.07 \mathrm{M} \$$

Subtotal $706.34 \mathrm{M} \$$

Installation and Commissioning at $30 \%$

$211.90 \mathrm{M} \$$

Direct Cost Total 918.24 M\$ 


\section{$\underline{\text { References }}$}

1. J. Hovingh et al., Fusion Technology, 13, No. 2, Feb. 1988, 255.

2. Final Report of the Technical Panel on Magnetic Fusion of the Energy Research Advisory Board (DoE Fusion Policy Advisory Committee) September, 1990.

3. M.J. Monsler, The Potential for Reducing the Cost of a Heavy Ion Accelerator for ICF, Satori Technology, Final Report PO\#9056305 to LLNL Laser Fusion Program, Feb. 25, 1987.

4. ERDA Summer Study of Heavy Ions for Inertial Fusion, LBL-5543, Dec. 1976.

5. Proceedings of International Heavy Ion Fusion Symposium, Monterey, CA, Dec. 1990.

6. B. Badger et al., HIBALL-II, FPA-84-4, KFK-3840, UWFDM-625, Dec. 1984.

7. T. Godlove, Private Communication.

8. J. Barnard, et.al., Study of Recirculating Induction Accelerators as Drivers for Heavy Ion Fusion, LLNL report UCRL-LR-108095, 1991.

9. M. G. Tiefenback and D. Keefe, "Measurements of Stability Limits for a Space-ChargeDominated Ion Beam in a Long A. G. Transport Channel, IEEE Trans. Nucl. Sci, NS-32, 5, 2483, (1985).

10. M. Meuth et al., Nuc. Inst. and Methods in Phys. Res. A278 153, (1989).

11. Induction Linac Systems Experiments - Conceptual Engineering Design Study, LBL PUB5219, March 1989.

12. C. Fong et al., Intermediate Test Facility and Required Technology Development, May 1990, LBL HIFAR-Note 269.

13. C. Fong, et al., 4 MJ Comparison Driver, LBL HIFAR-Note, Jan. 1991. 
14. R. Bangerter and D. Ho, HIFAN-470, Proceedings of the 1990 Linac Conference, September 10-14, 1990, Albuquerque, NM. These results have been adopted for the current DOE/OFE funded study of power generation by inertial fusion.

15. D. Zuckerman et al., Fusion Technology, 13, No. 2, Feb. 1988, 226.

16. I. Haber and C. Celata, Private Communication.

17. A recent derivation of beam envelope relations is: E. Lee, The Beam Envelope Equation Systematic Solution for a Periodic Quadrupole Lattice with Space Charge, LBL report: LBL37050, UC-414, HIFAN 701, 1995. 


\section{Appendix}

\section{Approximate Relations for Intense Beam Transport(17)}

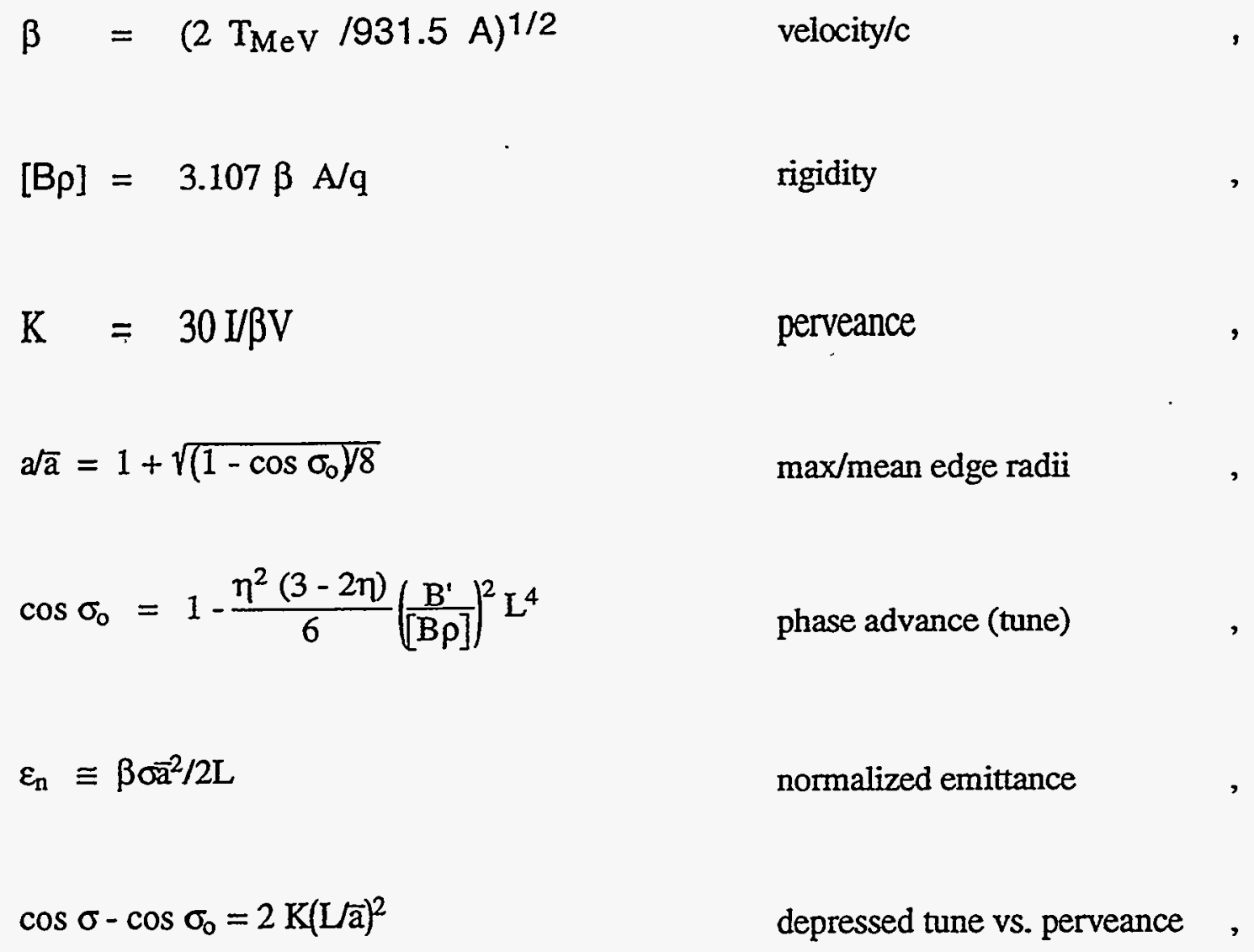




\section{Figure Captions}

Fig. 1 Layouts of Heavy Ion Drivers for power plants.

Fig. 2. Range-energy relation for ions in Aluminum ( $\left.200 \mathrm{eV}, .2 \mathrm{gm} / \mathrm{cm}^{2}\right)$.

Fig. 3. Gain curves for indirectly driven targets giving as a function of driver energy, focal spot radius, and ion range. These curves assume two-sided irradiation.

Fig. 4. Peak power requirements corresponding to the gain curves given in Fig. 3.

Fig. 5 Heavy Ion and Laser-Driven Targets

Fig. 6. Beam geometry

Fig. 7. Induction module

Fig. 8. Final focus layout. Magnet entire lengths, positions and aperture radii are depicted by vertical rectangles. Diagonal lines are the vertical $(V)$ and horizontal $(H)$ beam radii. A simple point-to-point focus is achieved with all focal lengths $F=4.0 \mathrm{~m}$. 
A. RF - LINAC / STORAGE RINGS

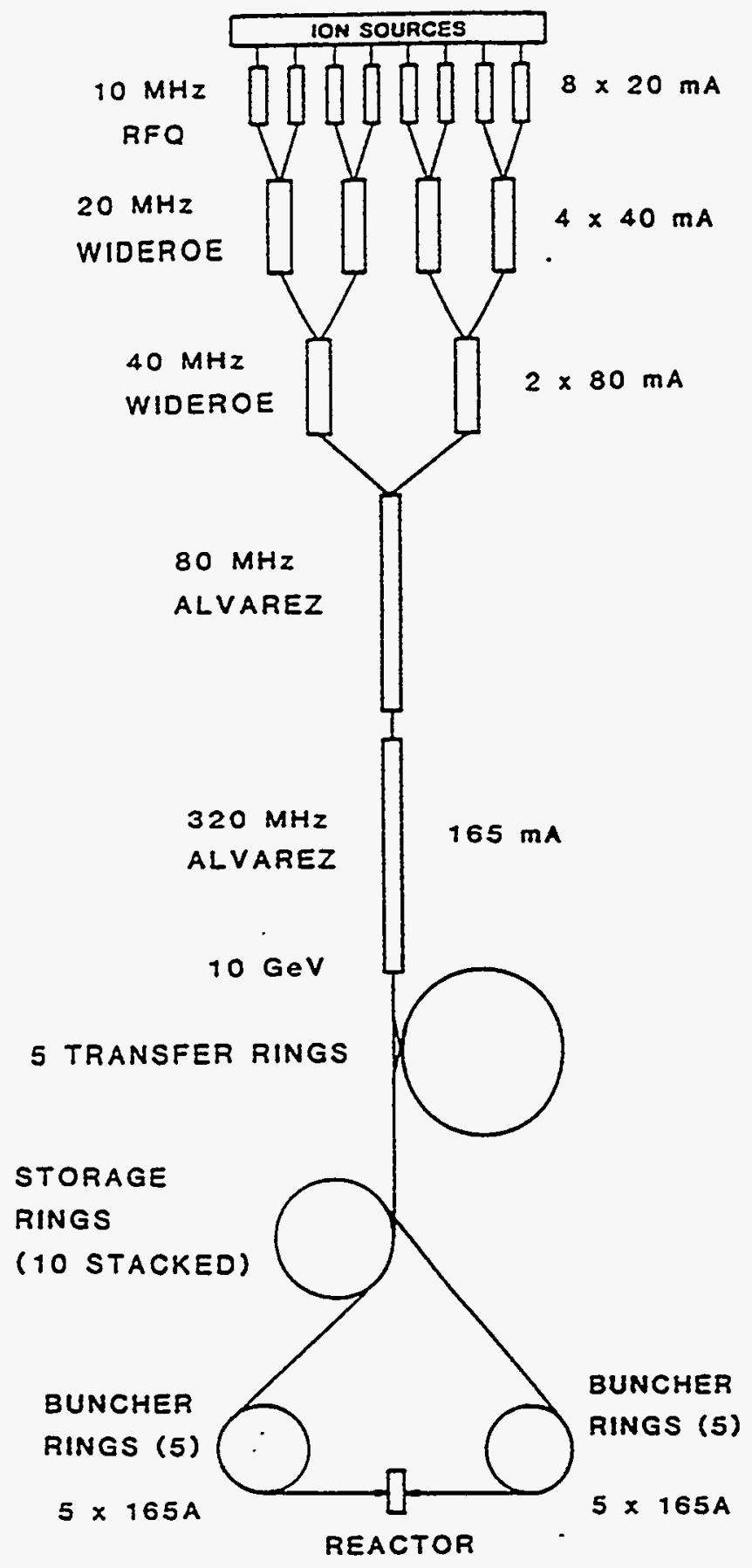

B. INDUCTION LINAC

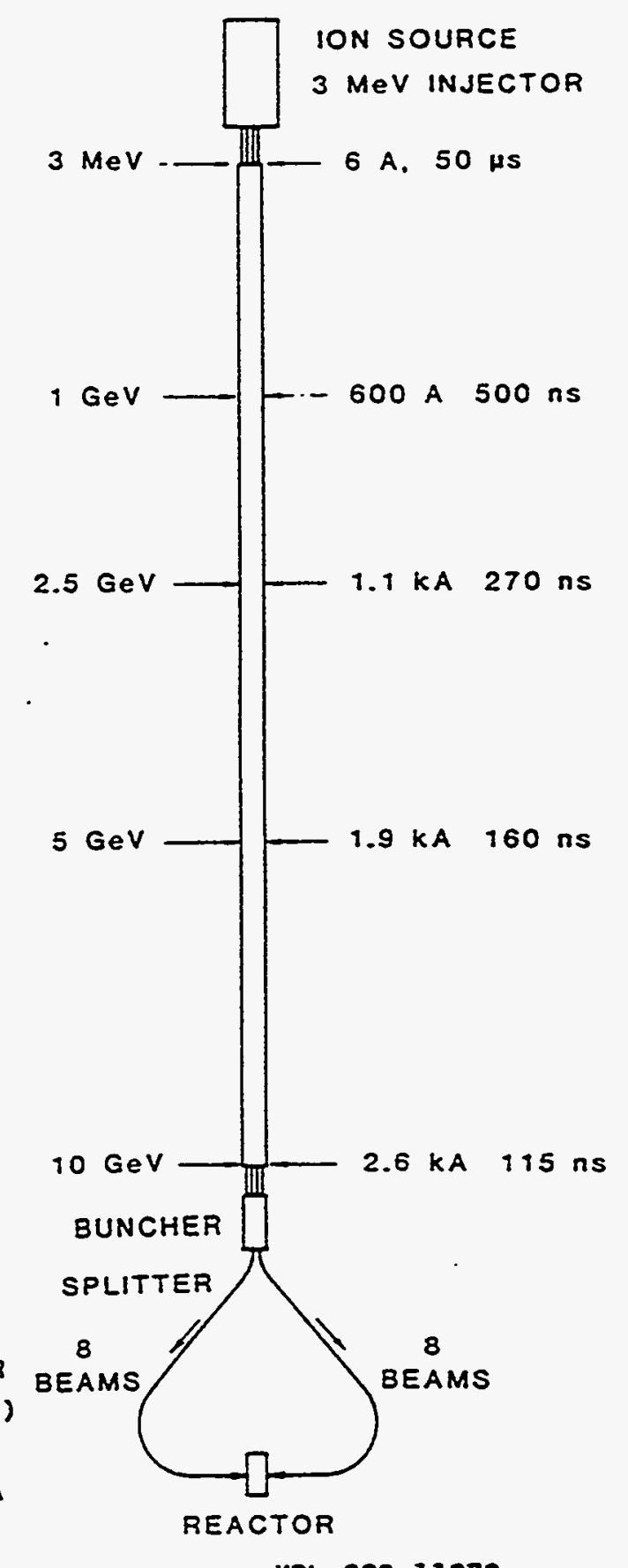

XBL $839-11373$

Figure I 


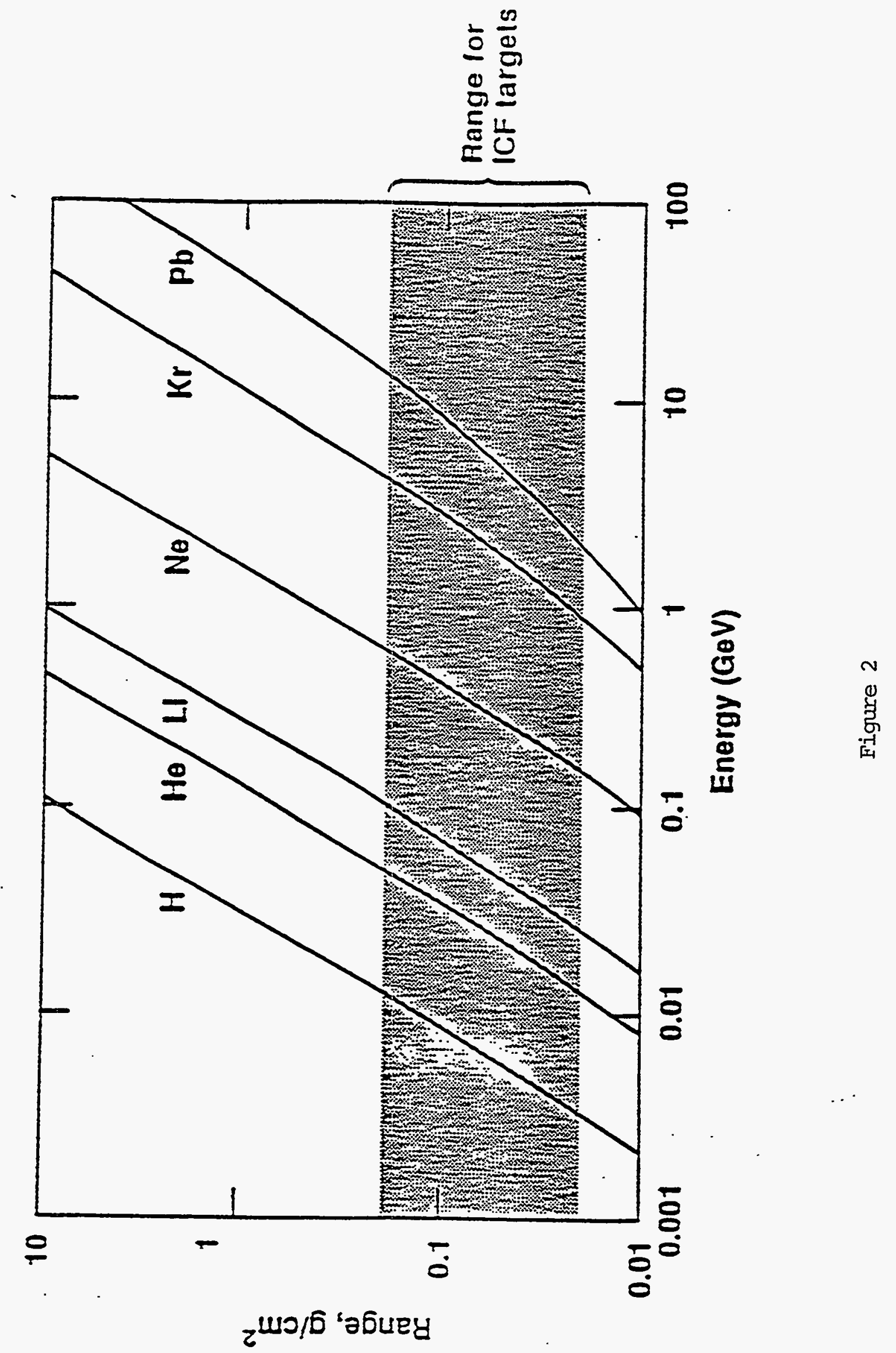




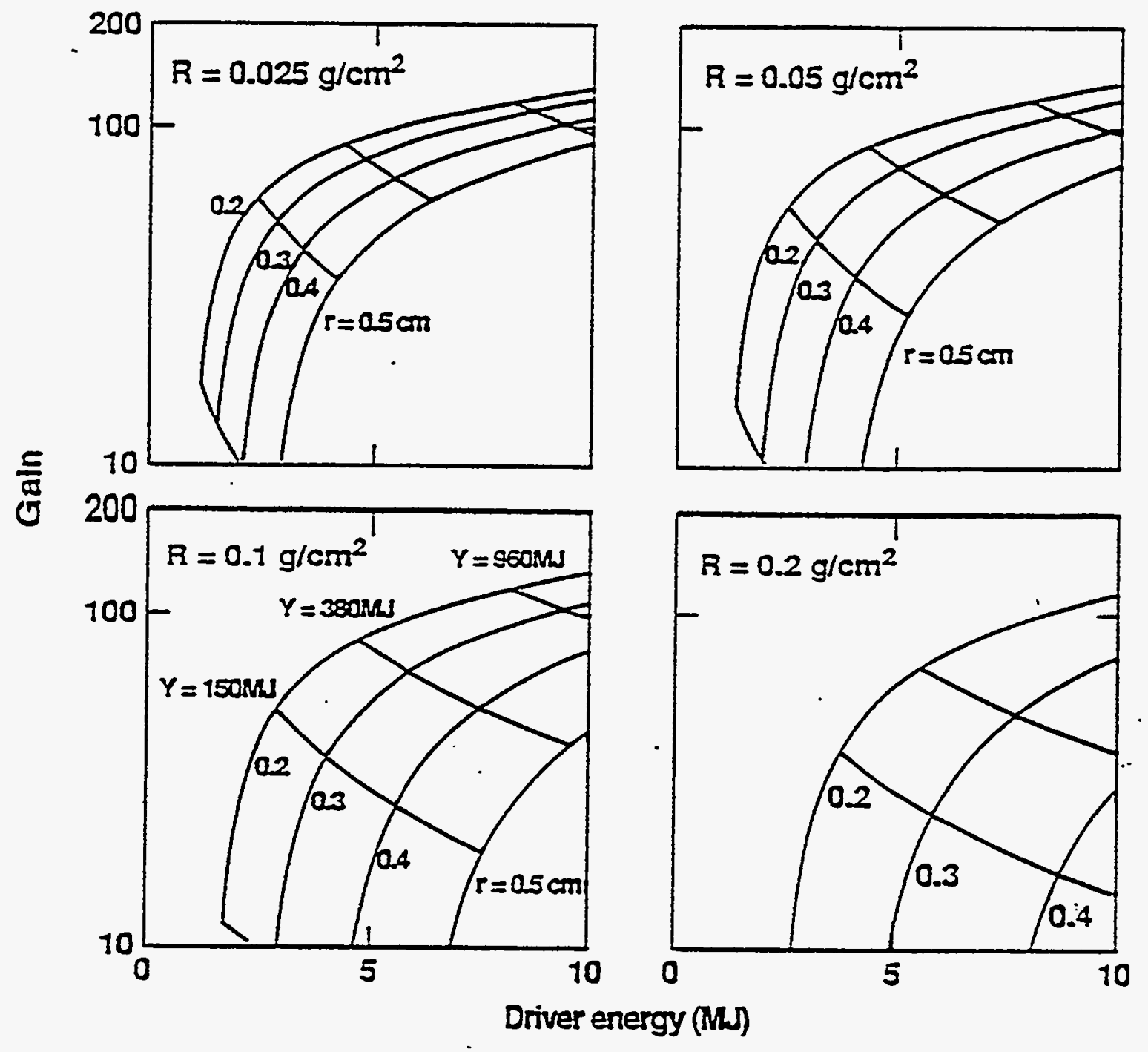

Figure 3 


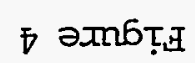

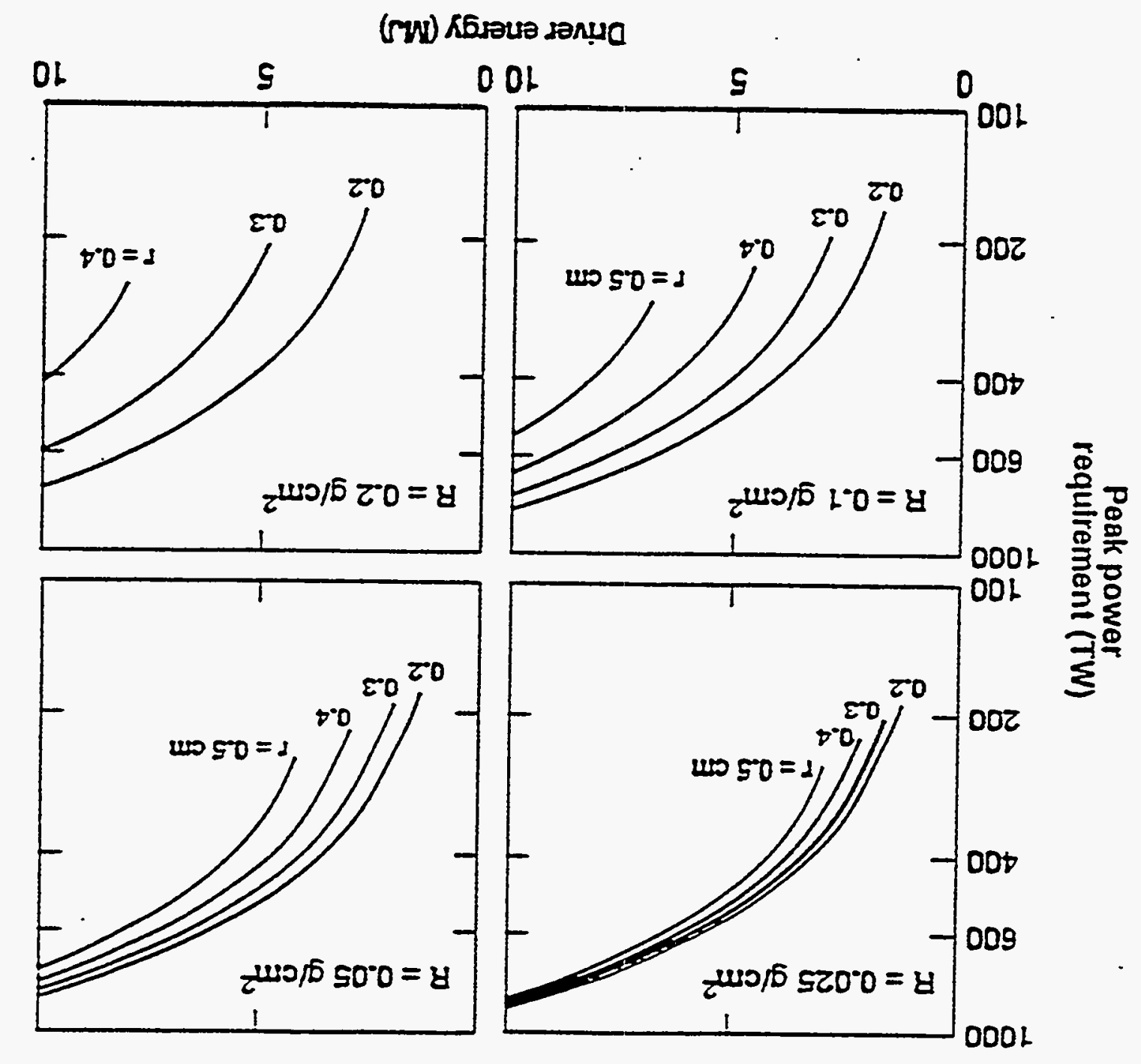




\section{For indirect drive, capsule physics is essentially driver-independent}

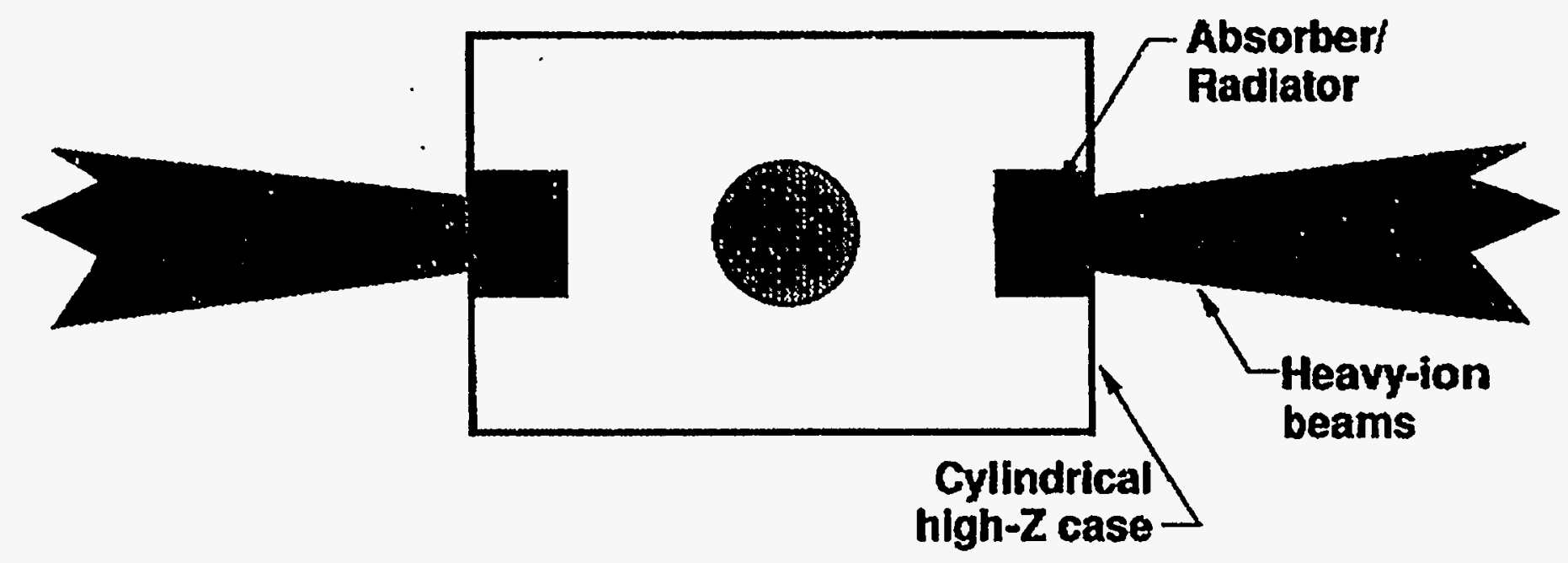

Heavy-lon Target

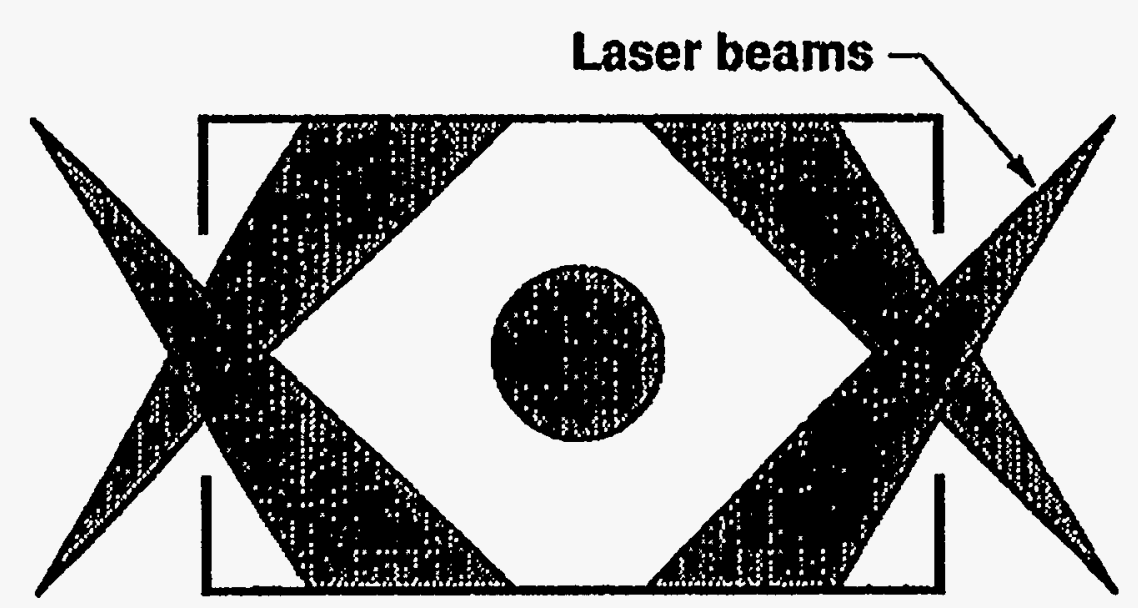

Laser Target 


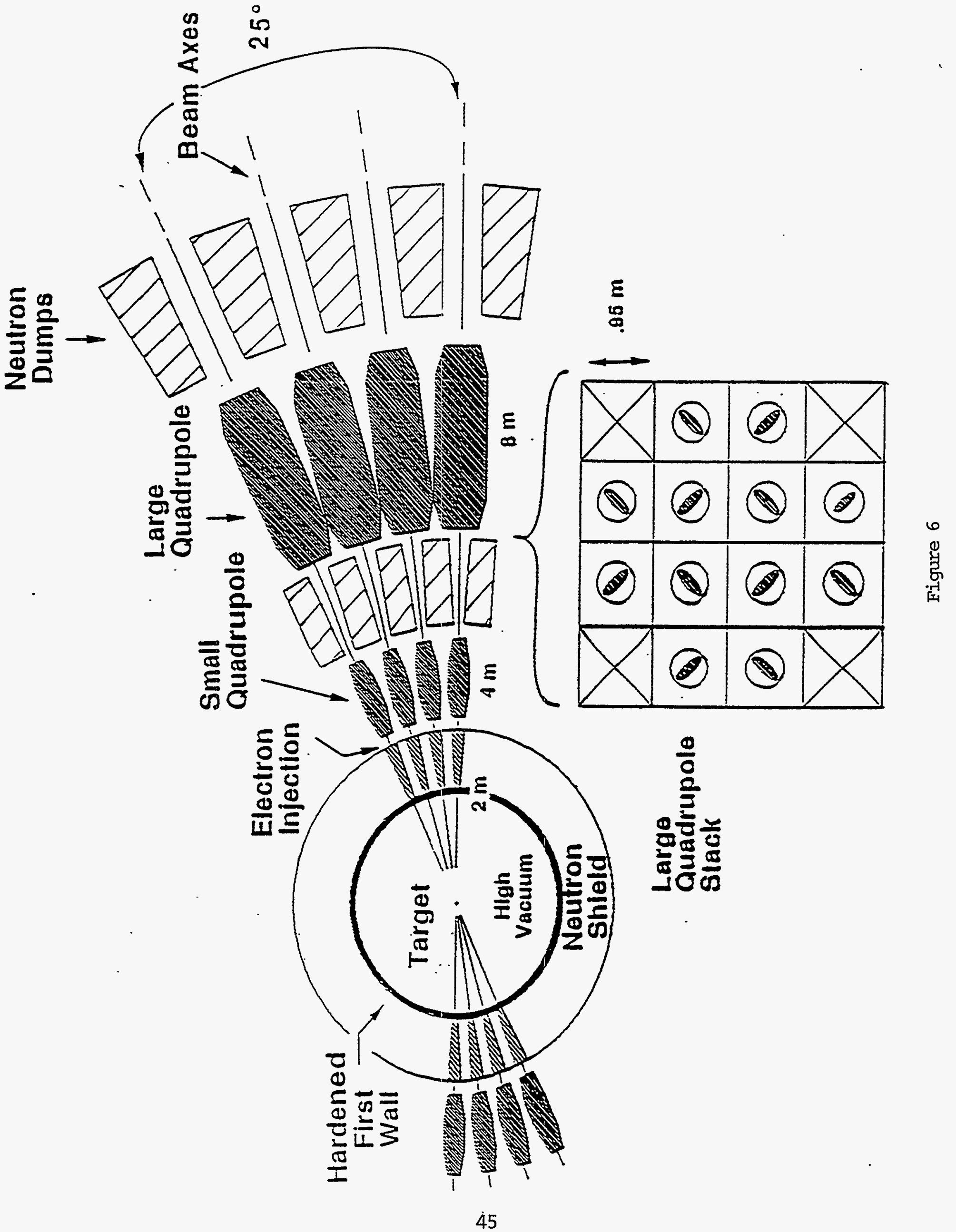




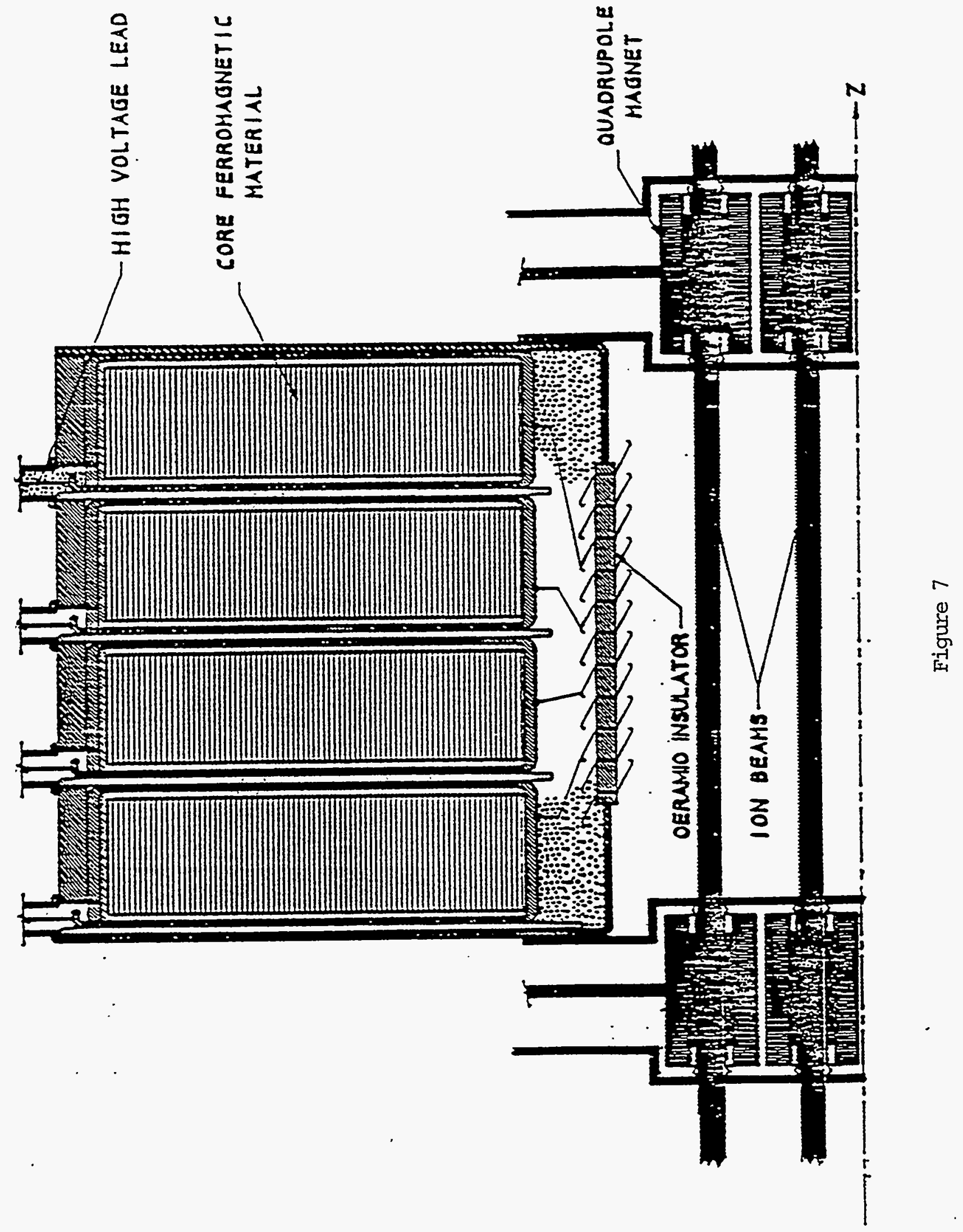




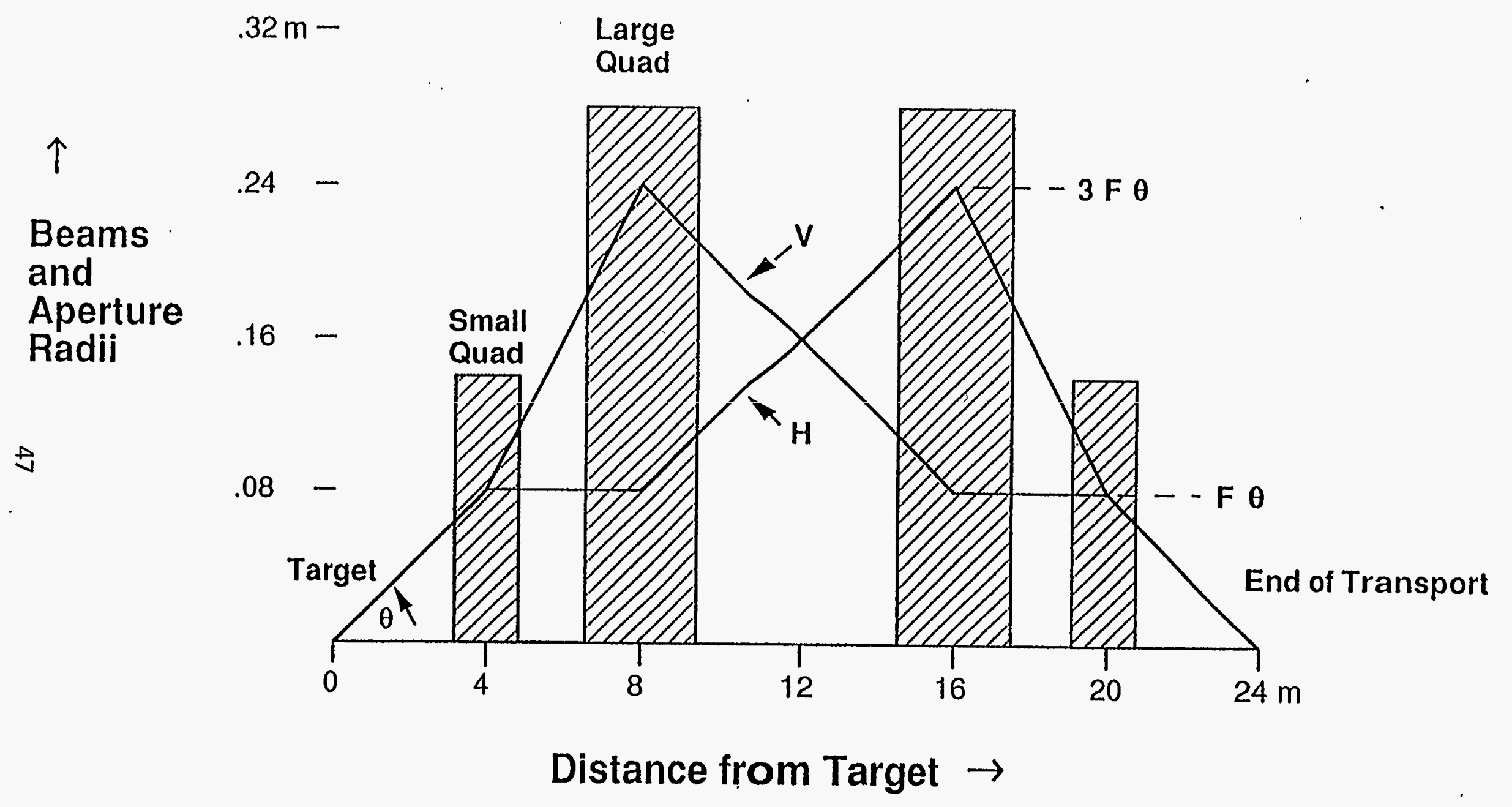

Figure 8 


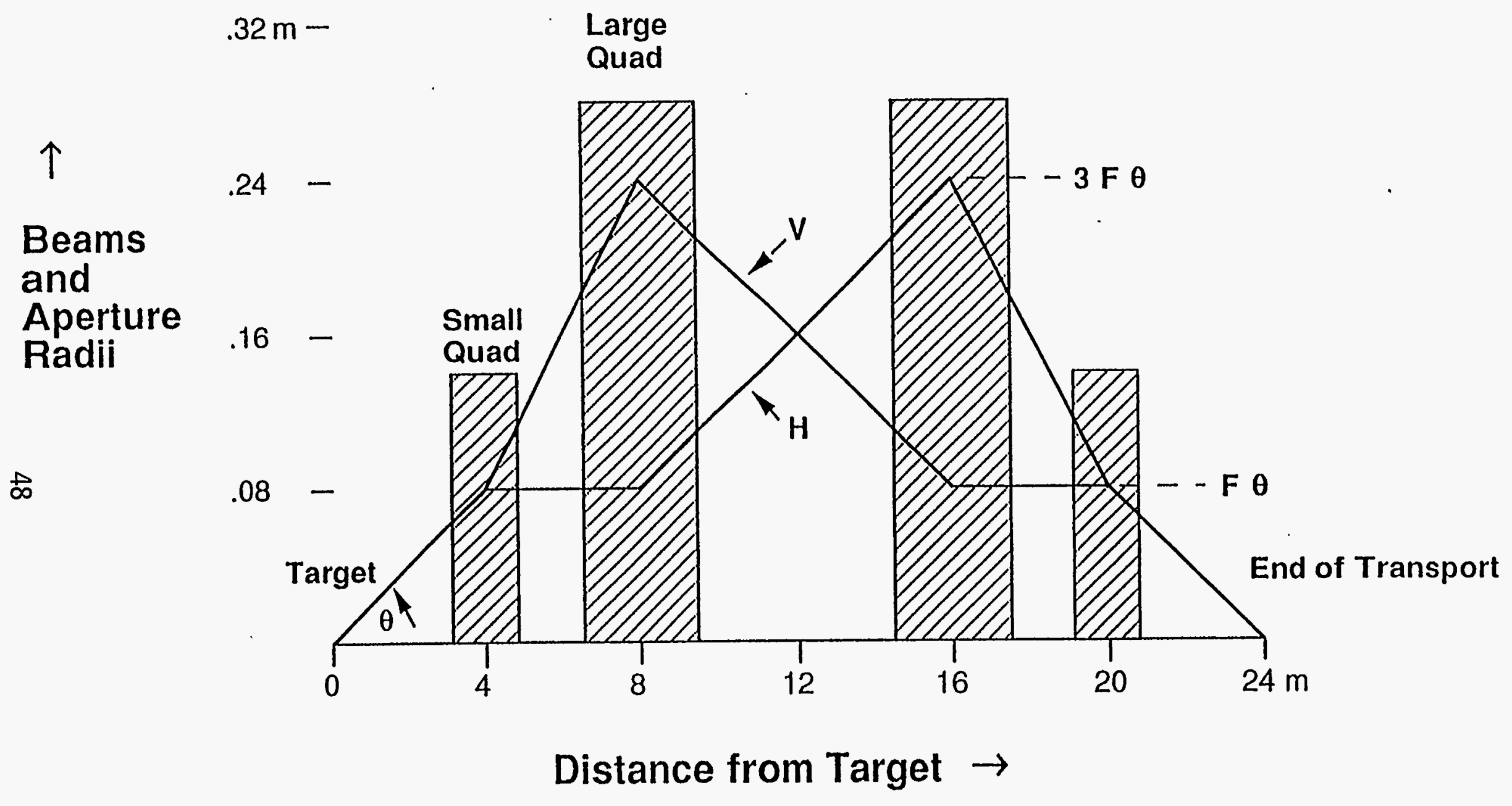

Figure 8 